Article

\title{
Generalized Least Energy of Separation for Desalination and Other Chemical Separation Processes
}

\author{
Karan H. Mistry and John H. Lienhard V* \\ Department of Mechanical Engineering, Massachusetts Institute of Technology, Cambridge, \\ MA 02139, USA; E-Mail: mistry@ mit.edu \\ * Author to whom correspondence should be addressed; E-Mail: lienhard@ mit.edu.
}

Received: 22 April 2013; in revised form: 14 May 2013 / Accepted: 22 May 2013 /

Published: 27 May 2013

\begin{abstract}
Increasing global demand for fresh water is driving the development and implementation of a wide variety of seawater desalination technologies driven by different combinations of heat, work, and chemical energy. This paper develops a consistent basis for comparing the energy consumption of such technologies using Second Law efficiency. The Second Law efficiency for a chemical separation process is defined in terms of the useful exergy output, which is the minimum least work of separation required to extract a unit of product from a feed stream of a given composition. For a desalination process, this is the minimum least work of separation for producing one kilogram of product water from feed of a given salinity. While definitions in terms of work and heat input have been proposed before, this work generalizes the Second Law efficiency to allow for systems that operate on a combination of energy inputs, including fuel. The generalized equation is then evaluated through a parametric study considering work input, heat inputs at various temperatures, and various chemical fuel inputs. Further, since most modern, large-scale desalination plants operate in cogeneration schemes, a methodology for correctly evaluating Second Law efficiency for the desalination plant based on primary energy inputs is demonstrated. It is shown that, from a strictly energetic point of view and based on currently available technology, cogeneration using electricity to power a reverse osmosis system is energetically superior to thermal systems such as multiple effect distillation and multistage flash distillation, despite the very low grade heat input normally applied in those systems.
\end{abstract}

Keywords: least work of separation; Second Law efficiency; cogeneration; power production; exergy 


\section{Nomenclature}

Roman symbols

a activity

$E \quad$ electromotive force

$e \quad$ electron charge

$F \quad$ Faraday constant

$g \quad$ specific Gibbs free energy

$\bar{g} \quad$ molar Gibbs free energy

$\bar{h} \quad$ molar enthalpy

$h_{f g} \quad$ latent heat of vaporization

I current

$K_{\text {eq }}$ equilibrium constant

$K_{\text {sp }} \quad$ solubility constant

$M \quad$ molecular weight

$\dot{m}$ mass flow rate

$m_{i} \quad$ molality of species $i$

$\dot{N} \quad$ mole flow rate

$N_{a} \quad$ Avogadro's number

$n \quad$ number of species

$n_{e} \quad$ number of electrons

$p \quad$ pressure

$\dot{Q} \quad$ rate of heat transfer

$Q \quad$ reaction quotient

$R \quad$ gas constant

$r \quad$ recovery ratio

$S$ entropy

$\dot{S}_{\text {gen }} \quad$ rate of entropy generation

$\bar{s} \quad$ molar entropy

$T$ temperature

$t$ time

$U \quad$ internal energy

$V \quad$ volume

$\dot{W} \quad$ rate of work

$x_{i} \quad$ mole fraction

$y \quad$ salinity

Greek

$\eta_{I I} \quad$ Second Law/exergetic efficiency

$\eta_{p p} \quad$ Second Law efficiency of power plant

$\gamma_{i} \quad$ molal activity coefficient of species

$\mu_{i} \quad$ chemical potential

$\mathrm{kJ} / \mathrm{mol}$
Units

- $\Xi$ exergy $\mathrm{kJ}$

$\mathrm{V} \quad \dot{\Xi}$ rate of exergy $\mathrm{kW}$

$\mathrm{C}$

$\mathrm{C} / \mathrm{mol} \quad \xi \quad$ specific exergy

$\mathrm{kJ} / \mathrm{kg}$

$\mathrm{kJ} / \mathrm{kg} \quad \bar{\xi} \quad$ molar exergy $\mathrm{kJ} / \mathrm{mol}$

$\mathrm{kJ} / \mathrm{mol}$

$\mathrm{kJ} / \mathrm{mol}$

$\mathrm{kJ} / \mathrm{kg}$

A

$\zeta \quad$ reaction coordinate

$\nu \quad$ stoichiometric coefficient

\section{Subscripts}

$\mathrm{kg} / \mathrm{mol} \quad 0 \quad$ dead state

$\mathrm{kg} / \mathrm{s}$

$\mathrm{mol} / \mathrm{kg} \quad a \quad$ assist

$\mathrm{mol} / \mathrm{s}$

$1 / \mathrm{mol}$

- $\quad H \quad$ high temperature

$\mathrm{kPa} \quad d \quad$ desalination plant

$\mathrm{kW} \quad f \quad$ feed

$\mathrm{J} / \mathrm{mol} \mathrm{K}$ in input

$\mathrm{kg}_{\text {product }} / \mathrm{kg}_{\text {feed }} \quad$ least reversible process in which all process

$\mathrm{kJ} / \mathrm{K} \quad$ streams cross the system boundary at the

$\mathrm{kW} / \mathrm{K}$

$\mathrm{kJ} / \mathrm{mol} \mathrm{K}$

RDS

$\mathrm{K} \quad p p \quad$ power plant

S $\quad p \quad$ product

$\mathrm{m}^{3} \quad r \quad$ reaction

$\mathrm{kW}$

$\mathrm{kg}_{\text {solutes }} / \mathrm{kg}_{\text {solution }} \quad$ sep amount required for separation process

Units $\quad s \quad$ steam temperature

$+\quad$ cation

- anion 


\section{Superscripts \\ min minimum value at infinitesimal recovery \\ - reference state}

\section{Acronyms}

ED electrodialysis

ERD energy recovery device

GOR gained output ratio

$\mathrm{HDH}$ humidification-dehumidification

LHS left hand side

MD membrane distillation
MED multiple effect distillation

MSF multistage flash

MVC mechanical vapor compression

PRO pressure retarded osmosis

RDS restricted dead state

RED reverse electrodialysis

RHS right hand side

RO reverse osmosis

SGE salinity gradient engine

TDS total dead state

\section{Introduction}

Growing water demand due to rising population, increasing standards of living, and industrialization is resulting in substantial water shortage and scarcity. While developing countries are often hardest hit by lack of water supply, developed countries have had to face these issues as well [1,2]. Substantial research in desalination technologies has occurred in recent decades in order to develop more efficient and economical methods, both to provide potable water and to remediate industrial process waters $[3,4]$.

Currently, several different technologies for desalinating water are in wide use, including reverse osmosis (RO), multistage flash (MSF), multiple effect distillation (MED), among others. These systems are powered by electricity (work), heat, or some combination thereof. The description of energy requirements becomes more complicated when one considers that many larger scale water plants are operated in conjunction with power plants in a cogeneration scheme [5]. While advances over the last several decades have resulted in dramatically reduced energy utilization, desalination is still energy intensive, and it is important to be able to fully characterize the performance of these systems and to compare the relative energy costs from system to system. Second Law efficiency is a parameter that can be used to compare the thermodynamic performance of systems.

Second Law analysis has been applied to desalination systems in past studies [6-12], but many conflicting definitions for Second Law efficiency have been applied. In a previous paper, the authors showed that for desalination systems, Second Law efficiency should be defined in terms of the least work of separation [13]. The least work of separation $\left(\dot{W}_{\text {least }}\right)$ represents the least amount of work required to reversibly separate a single stream into multiple streams of different composition [5,7,13-15]. Similarly, the least heat of separation $\left(\dot{Q}_{\text {least }}\right)$ can be used to represent the least amount of heat required for a separation process. Both are benchmarks to which desalination systems are compared, much as Carnot efficiency is the ideal benchmark to which power plants are compared.

While the least work and least heat of separation are useful parameters for work and heat driven systems respectively, it is difficult to directly compare the energies represented by least work and least heat. Additionally, these parameters are only useful for systems that have a single energy source (work or heat only). Many modern separation processes, including most thermal desalination systems (e.g., MSF and MED), require both thermal and mechanical energy input. Still other systems may be powered by 
chemical energy. Therefore, a more useful least energy metric would capture simultaneous mechanical, thermal, and chemical energy inputs.

This paper builds on the work of Mistry et al. [13] and generalizes the least energy of separation calculation to a generic chemical separator. Further, the Second Law efficiency definitions are likewise generalized so that they may be applied to systems that utilize some combination of mechanical, thermal, or chemical energy inputs. A "least" separation process is defined here as a completely reversible process in which the minimum amount of energy, as required by the Second Law of Thermodynamics, is needed to drive a chemical separation process. This concept is clarified and further developed through several examples. Finally, the Second Law efficiency of a desalination plant in a cogeneration scheme is studied through a parametric analysis.

\section{Generalized Least Energy of Separation for Chemical Separation Processes}

The equation for the generalized least energy of separation is derived using the generalized exergy equation for an arbitrary system control volume shown in Figure 1 [16]. This control volume has $q$ inlet streams and $r$ outlet streams, each potentially at different temperature, pressure, and chemical composition of 0 to $n$ species. For simplicity, kinetic and potential energy is neglected. The system is in thermal contact with $p$ heat reservoirs and is free to transfer work $\left(p_{0} \mathrm{~d} V / \mathrm{d} t\right)$, heat $\left(\dot{Q}_{0}\right)$, and mass $\left(\dot{N}_{0, i}\right)$ with the environment. In Figure 1 and the subsequent equations, the subscript 0 is used to denote environmental conditions and the subscript $i$ is used to denote a specific species (e.g., $\dot{N}_{0, i}$ is the mole flow rate of species $i$ into the system, from the environment at $T_{0}, p_{0}$ with a chemical potential of $\mu_{0, i}$ ). The sign convention of positive work input is used herein. As a result, the outlet streams can leave the system at thermal, mechanical, and chemical equilibrium with the environment. That is, they can leave the system at the total dead state (TDS). The First and Second Laws of Thermodynamics are written for the control volume as follows:

$$
\begin{aligned}
\frac{\mathrm{d} U}{\mathrm{~d} t} & =\dot{W}+\sum_{l=0}^{p} \dot{Q}_{l}+\sum_{j=1}^{q} \dot{N}_{j} \bar{h}_{j}-\sum_{k=1}^{r} \dot{N}_{k} \bar{h}_{k}+\sum_{i=1}^{n} \dot{N}_{0, i} \bar{h}_{0, i}-p_{0} \frac{\mathrm{d} V}{\mathrm{~d} t} \\
\frac{\mathrm{d} S}{\mathrm{~d} t} & =\sum_{l=0}^{p} \frac{\dot{Q}_{l}}{T_{l}}+\sum_{j=1}^{q} \dot{N}_{j} \bar{s}_{j}-\sum_{k=1}^{r} \dot{N}_{k} \bar{s}_{k}+\sum_{i=1}^{n} \dot{N}_{0, i} \bar{s}_{0, i}+\dot{S}_{\text {gen }}
\end{aligned}
$$

Equations (1) and (2) are combined by eliminating $\dot{Q}_{0}$, conserving mass, and accounting for volume change of the control volume resulting in the generalized exergy equation for an open system [16]:

$$
\frac{\mathrm{d} \Xi_{t}}{\mathrm{~d} t}=\dot{\Xi}_{W}+\sum_{l=1}^{p} \dot{\Xi}_{\dot{Q}, l}+\sum_{j=1}^{q} \dot{N}_{j} \bar{\xi}_{j}-\sum_{k=1}^{r} \dot{N}_{k} \bar{\xi}_{k}-T_{0} \dot{S}_{\text {gen }}
$$


where

$$
\begin{aligned}
\Xi_{t} & =U-T_{0} S+p_{0} V-\sum_{i=1}^{n} \mu_{0, i} N_{i} \\
\dot{\Xi}_{\dot{W}} & =\dot{W} \\
\dot{\Xi}_{\dot{Q}} & =\left(1-\frac{T_{0}}{T}\right) \dot{Q} \\
\bar{\xi}\left(T, p, N_{i}\right) & =\bar{h}\left(T, p, N_{i}\right)-T_{0} \bar{s}\left(T, p, N_{i}\right)-\sum_{i}^{n} \mu_{0, i}\left(T_{0}, p_{0}\right) x_{i}
\end{aligned}
$$

While Equation (3) is completely general and applicable to any open system, it can be simplified to be more useful when applied specifically to chemical separation processes. An arbitrary chemical separation process can be powered by mechanical, thermal, or chemical energy. While mechanical and thermal energy inputs are represented by work and heat transfer respectively, chemical energy is input to the system through the inflow and outflow of fuel and exhaust streams. In a chemical separation process, it is important to differentiate between process streams and fuel/exhaust streams. Process streams are any streams directly involved in the chemical separation process and include feed, product, and any waste streams. For a desalination system, this would typically include seawater (feed), pure water (product), and concentrated brine (waste). For an oil separation process, this would include crude oil (feed), various grades of refined hydrocarbons (products), and solid waste. The terms fuel and exhaust are used loosely to represent all streams that are used to provide energy to the system such as fuel, solvents, air, and combustion products. The mole flow rate summation terms in Equation (3) are rearranged into sums over the inlets minus the outlets of the process streams and the fuel/exhaust streams. All of the energy inputs are moved to the left hand side (LHS) of the equation and all the process streams, stored energy, and irreversibilities are moved to the right hand side (RHS).

$$
\dot{\Xi}_{\dot{W}}+\sum_{l=1}^{p} \dot{\Xi}_{\dot{Q}_{l}}+\underbrace{\sum_{\text {in-out }} \dot{N} \bar{\xi}}_{\text {fuel and exhaust streams }}=\frac{\mathrm{d} \Xi_{t}}{\mathrm{~d} t}+\underbrace{\sum_{\text {out-in }} \dot{N} \bar{\xi}}_{\text {process streams }}+T_{0} \dot{S}_{\text {gen }}
$$

The LHS of Equation (8) represents all exergy inputs to the system while the RHS represents the changes associated with the control volume and process streams. Using this equation, the generalized least energy of separation is derived. Consider the RHS first. In order to minimize the required exergetic input, the process must be reversible. Additionally, any thermal and mechanical energy in the exit process streams is considered wasted since the desired product in a separation process is the mass of product. This concept is discussed in detail by Mistry et al. [13]. Therefore, the process streams must exit at the restricted dead state (RDS). Note that the process streams cannot leave at the TDS since the purpose of a chemical separation process is to convert an inlet stream into streams with different composition and allowing chemical equilibrium to occur would have the net effect of undoing the separation process. Under these conditions, the exergy of the process streams reduces to the Gibbs free energy at atmospheric temperature and pressure.

$$
\bar{\xi}\left(T_{0}, p_{0}, N_{i}\right)=\bar{h}\left(T_{0}, p_{0}, N_{i}\right)-T_{0} \bar{s}\left(T_{0}, p_{0}, N_{i}\right) \equiv \bar{g}\left(T_{0}, p_{0}\right)
$$


Equation (8) is simplified by substituting Equation (9) into the process stream summation, substituting in Equations (5) and (6), assuming steady state, and assuming reversible behavior. This leaves the generalized least energy of separation equation:

$$
\underbrace{\dot{W}+\sum_{l=1}^{p}\left(1-\frac{T_{0}}{T}\right)_{l} \dot{Q}_{l}}_{\text {energy inputs/outputs }}+\underbrace{\sum_{\text {in-out }} \dot{N} \bar{\xi}\left(T, p, N_{i}\right)}_{\text {fuel and exhaust streams }}=\underbrace{\sum_{\text {out-in }} \dot{N} \bar{g}\left(T_{0}, p_{0}, N_{i}\right)}_{\text {process streams }}
$$

The RHS of the equation represents the least amount of exergy required to separate the input process streams into output streams of different chemical compositions. For a desalination process, a feed stream is separated into a low salinity product stream and a high salinity concentrate stream.

$$
\dot{\Xi}_{\text {least }} \equiv \sum_{\text {out }- \text { in }} \dot{N} \bar{g}\left(T_{0}, p_{0}, N_{i}\right)
$$

This exergy must be provided to the system by a combination of work, heat, and chemical energy as indicated by the LHS of the equation. Equations (10) and (11) are derived from a control volume that surrounds the system and only considers the inputs and outputs to the system. They represent the true limit for the least exergy required for separation, regardless of what process occurs within the control volume. Therefore, all technologies, including those which utilize a carrier fluid that does not leave the system boundary, are subject to the energy conservation requirement given by Equation (10). Such technologies include forward osmosis (FO) [17-20], humidification-dehumidification (HDH) [7,21-25], and directional solvent extraction [26,27].

Figure 1. A generalized control volume with $q$ inlets, $r$ outlets, $p$ heat transfer inputs, and work input. The control volume can exchange work $\left(p_{0} \mathrm{~d} V / \mathrm{d} t\right)$, heat $\left(\dot{Q}_{0}\right)$, and mass $\left(\dot{N}_{0, i}\right)$ with the environment through the system boundary.

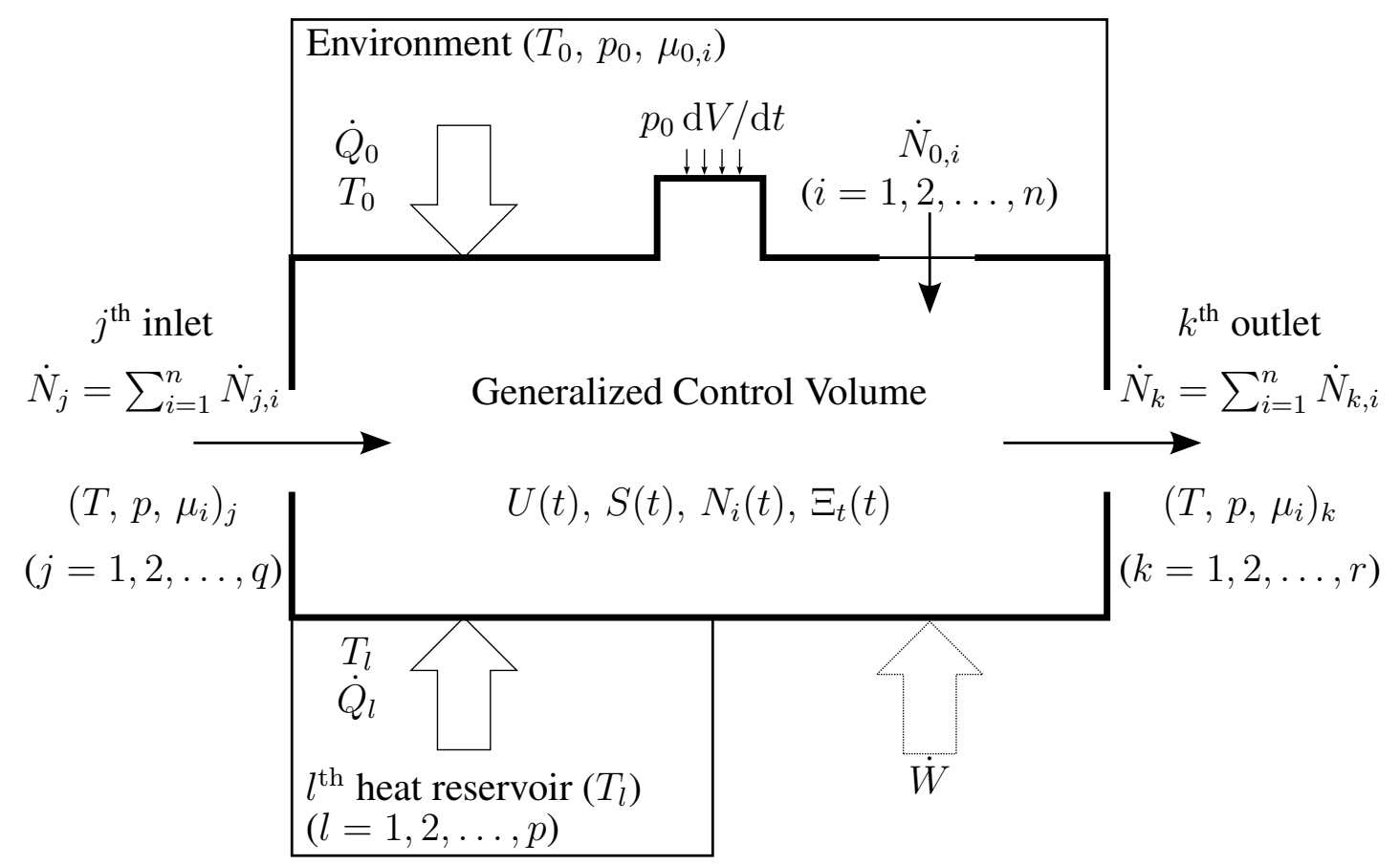


Since it is conventional to discuss desalination systems on a mass basis, rather than a mole basis, it is more convenient to write Equation (11) in terms of mass flow rates. For a system with one inlet stream (feed) and two outlet streams (product and concentrate), this is written as:

$$
\dot{\Xi}_{\text {least }}=\sum_{\text {out-in }} \dot{m} g\left(T_{0}, p_{0}, N_{i}\right)=\dot{m}_{p} g_{p}+\dot{m}_{c} g_{c}-\dot{m}_{f} g_{f}
$$

where $g_{j}$ is the specific Gibbs free energy per kilogram of solution and is a function of the temperature, pressure, and salinity of each of the dissolved species.

Recovery ratio is defined as the ratio of the mass flow rate of product water to the mass flow rate of feed water:

$$
r \equiv \frac{\dot{m}_{p}}{\dot{m}_{f}}=\frac{\text { mass flow rate of product }}{\text { mass flow rate of feed }}
$$

Equation (12) can be rewritten in terms of the recovery ratio by combining Equation (13) with conservation of mass:

$$
\dot{m}_{f}=\dot{m}_{p}+\dot{m}_{c}
$$

Normalizing by the product flow rate gives:

$$
\frac{\dot{\Xi}_{\text {least }}}{\dot{m}_{p}}=\left(g_{p}-g_{c}\right)-\frac{1}{r}\left(g_{f}-g_{c}\right)
$$

Evaluation of Equation (15) requires physical properties of the feed, product, and concentrate streams. While the Gibbs free energy can be evaluated by summing chemical potentials of each of the species [28-30], seawater property packages based upon a single salinity parameter are available [31-34]. The package by Sharqawy et al. [33,34] is used in this study. Correlations for properties such as specific Gibbs free energy, osmotic coefficients, and chemical potential of water and salts in seawater are given as a function of temperature and salinity. The range of validity of the correlations varies slightly for each property, but in general, they are available for temperatures in $0-120^{\circ} \mathrm{C}$ and salinities in $0-120 \mathrm{~g} / \mathrm{kg}$. By assuming that the relative concentration of each of the dissolved species is the same in each stream, conservation of mass for the salts is written as:

$$
\dot{m}_{f} y_{f}=\dot{m}_{p} y_{p}+\dot{m}_{c} y_{c}
$$

The Gibbs free energy of each of the streams in Equation (15) is evaluated using seawater properties, as a function of temperature and salinity, $g_{j}=g_{j}\left(T, y_{j}\right)$ [33]. With the feed and product salinities $\left(y_{f}, y_{p}\right)$ given, the concentrate salinity $\left(y_{c}\right)$ is evaluated using Equations (13), (14) and (16):

$$
y_{c}=\frac{y_{f}-r y_{p}}{1-r}
$$

Finally, as discussed by Mistry et al. [13], the minimum least exergy of separation occurs in the limit of infinitesimal recovery:

$$
\dot{\Xi}_{\text {least }}^{\min }=\lim _{r \rightarrow 0} \dot{\Xi}_{\text {least }}
$$

While $\dot{\Xi}_{\text {least }}^{\min }$ represents the least amount of exergy required to drive a separation process, it does not necessarily give design guidance as infinitesimal recovery would result in infinite cost. 
In the following sections, three special cases of Equation (10) are considered: least work of separation, least heat of separation, and least chemical energy of separation. These special cases occur when only one form of energy input is used.

\section{Least Work of Separation}

For chemical separation processes that are powered by work only, the schematic diagram shown in Figure 1 can be simplified. Examples of work-driven desalination systems include RO, mechanical vapor compression (MVC), and electrodialysis (ED). In the case of an arbitrary desalination system, the generalized control volume reduces to the schematic diagram illustrated in Figure 2. Note that while work is the only energy input, in order to fulfill the First and Second Laws of Thermodynamics and to allow all streams to enter and exit the control volume at ambient temperature, heat transfer must be allowed with the environment $\left(\dot{Q}_{0}\right)$.

Figure 2. A control volume for an arbitrary black box chemical separator powered by work only.

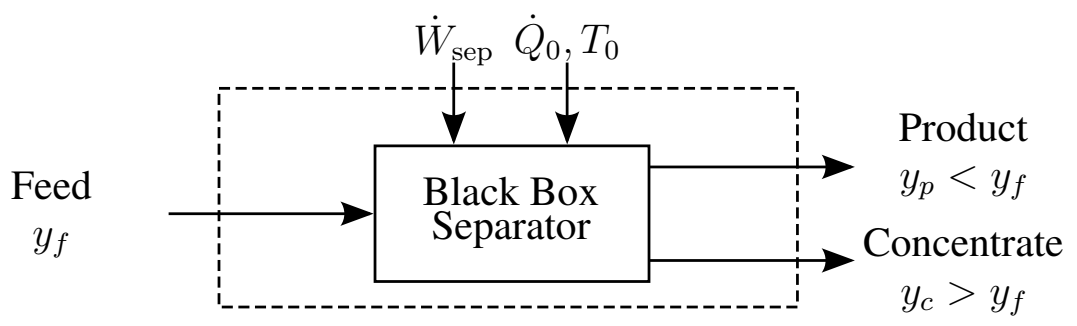

Simplifying Equation (10) to the arbitrary desalination system shown in Figure 2, with only work input and heat transfer from the environment, yields the definition of the least work of separation:

$$
\dot{W}_{\text {least }}=\sum_{\text {out-in }} \dot{N} \bar{g}\left(T_{0}, p_{0}, N_{i}\right)=\dot{\Xi}_{\text {least }}
$$

The least work and least exergy of separation are equivalent and the terms are used interchangeably in the remainder of this paper. Using Equations (15) and (19), the least work of separation is:

$$
\frac{\dot{W}_{\text {least }}}{\dot{m}_{p}}=\left(g_{p}-g_{c}\right)-\frac{1}{r}\left(g_{f}-g_{c}\right)
$$

Equation (20) is a function of temperature, feed salinity, product salinity, and recovery ratio and is plotted for various feed salinities and recovery ratios at a constant temperature of $25^{\circ} \mathrm{C}$ in Figure 3 . The least work of separation is a strong function of feed salinity and recovery ratio, and a weak function of the product salinity (for typically low product salinities). 
Figure 3. Least work of separation as a function of feed salinity and recovery ratio. Feed water is at $T_{0}=25^{\circ} \mathrm{C}$.

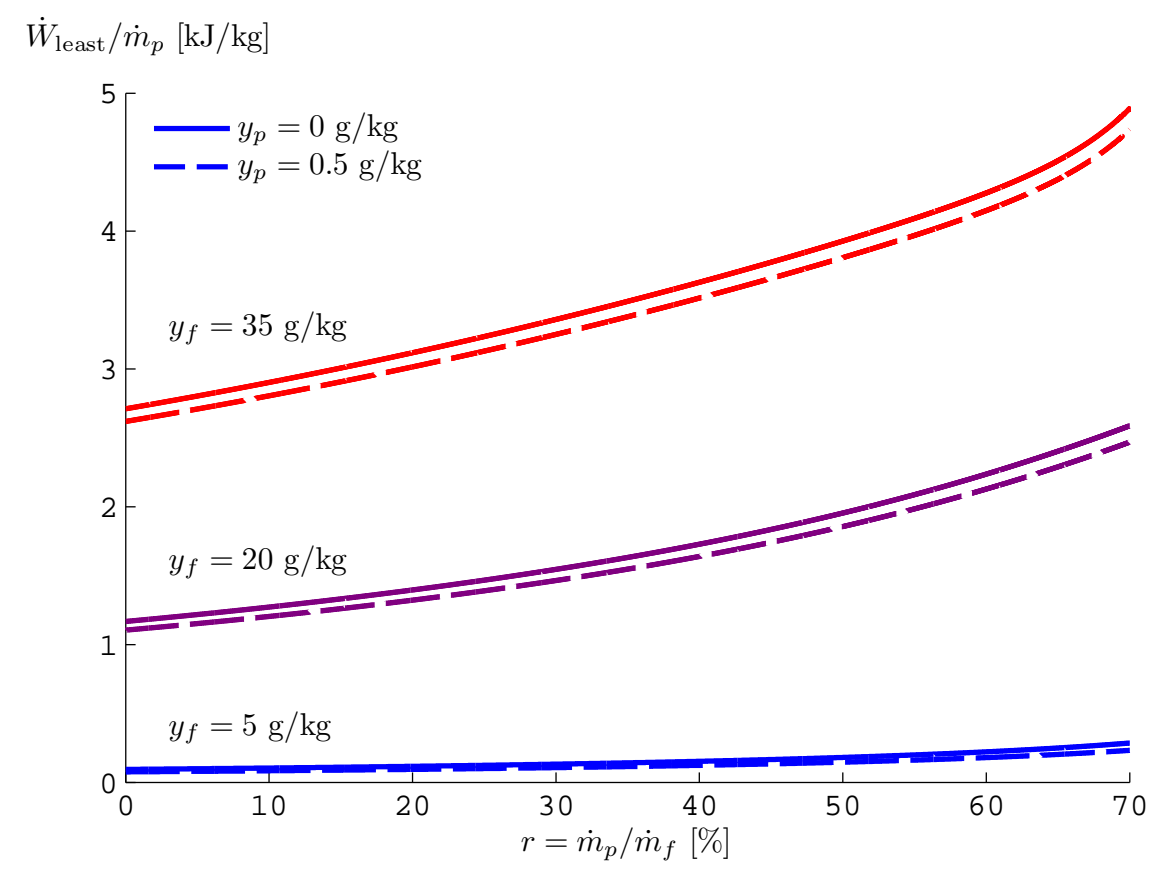

\section{Least Heat of Separation}

Chemical separation processes can be powered using only heat input. Examples of heat driven desalination systems include MED, MSF, membrane distillation (MD), and HDH. A schematic diagram of an arbitrary desalination plant powered using a high temperature heat source is shown in Figure 4. As with the work-driven case, this control volume allows for atmospheric heat transfer in order to satisfy the First and Second Laws of Thermodynamics. When heat is the only form of energy input, Equation (10) reduces to the least heat of separation:

$$
\dot{Q}_{\text {least }}=\left(1-\frac{T_{0}}{T_{H}}\right)^{-1} \sum_{\text {out }- \text { in }} \dot{N}_{j} \bar{g}_{j}\left(T_{0}, p_{0}, N_{i}\right)=\left(1-\frac{T_{0}}{T}\right)^{-1} \dot{W}_{\text {least }}
$$

For the arbitrary desalination system pictured in Figure 4, the least heat of separation can be expressed on a mass basis as follows:

$$
\frac{\dot{Q}_{\text {least }}}{\dot{m}_{p}}=\left(1-\frac{T_{0}}{T_{H}}\right)^{-1}\left[\left(g_{p}-g_{c}\right)-\frac{1}{r}\left(g_{f}-g_{c}\right)\right]
$$

Unlike the least work, $\dot{Q}_{\text {least }}$ is a function of the temperature at which the heat is transferred in addition to the ambient temperature, recovery ratio, and feed and product salinities. As with Carnot efficiency, it is clear that the least heat improves with increasing top temperature (Figure 5). In Figure 5, the least heat is evaluated at four different top temperatures: $50{ }^{\circ} \mathrm{C}, 75^{\circ} \mathrm{C}, 100{ }^{\circ} \mathrm{C}$, and $5800 \mathrm{~K}$. The first three represent a range of values typical of common thermal desalination methods. The high temperature represents an upper bound on the temperature at which energy can be transferred from the sun. At such high temperatures, the Carnot efficiency begins to approach one and $\dot{Q}_{\text {least }}$ approaches $\dot{W}_{\text {least }}$. 
Figure 4. A control volume for an arbitrary black box chemical separator when heat is the only form of energy input.

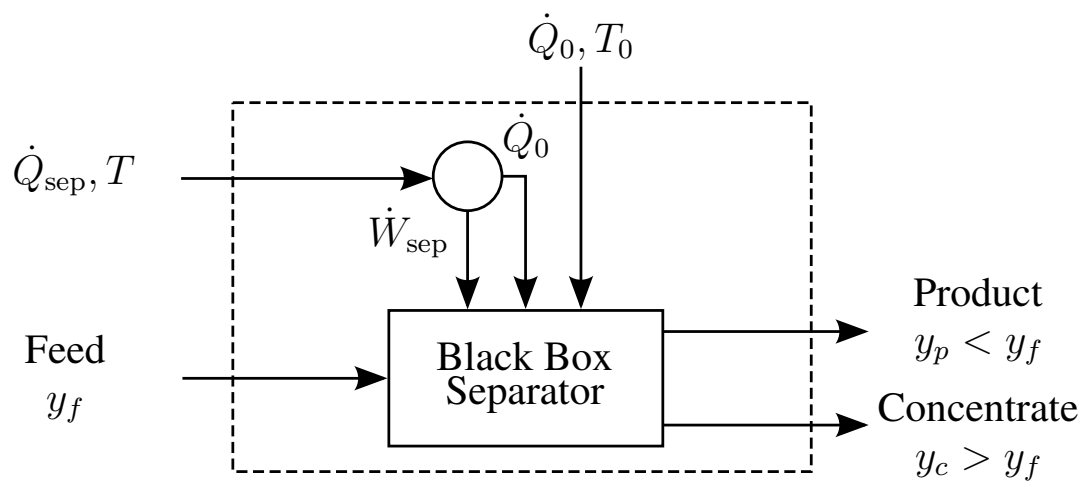

Figure 5. Least heat of separation as a function of feed salinity and recovery ratio. Feed water is at $T_{0}=25^{\circ} \mathrm{C}$ and $y_{f}=35 \mathrm{~g} / \mathrm{kg}$.

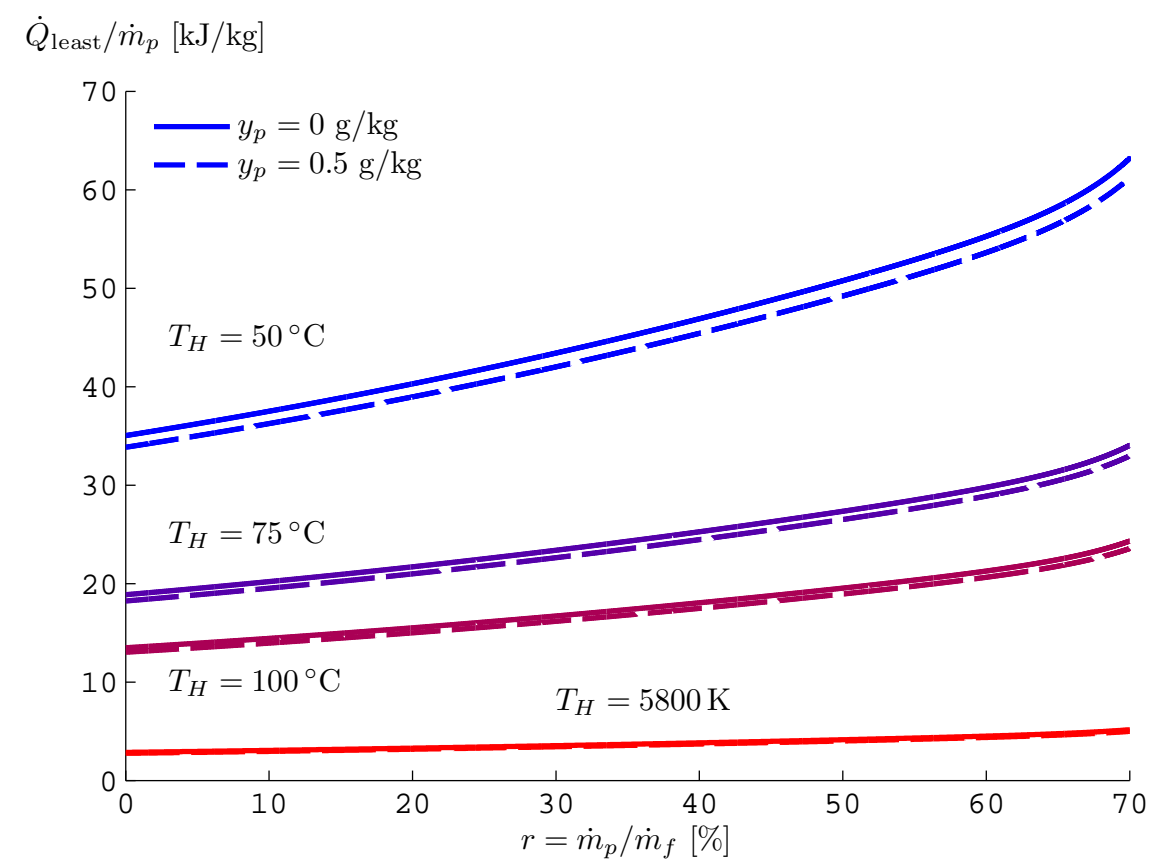

Gained output ratio (GOR) is a commonly used performance parameter in the thermal desalination industry. GOR is the ratio of the enthalpy required to evaporate the distillate (or equivalently, the energy release in condensation) to the heat input to the system:

$$
\mathrm{GOR} \equiv \frac{\dot{m}_{p} h_{f g}\left(T_{0}\right)}{\dot{Q}_{\mathrm{sep}}}
$$

Essentially, GOR is a direct measure of how many times the latent heat of vaporization is captured in the condensation of purified water vapor and reused in a subsequent evaporation process to create additional water vapor. The highest GOR possible for a given recovery ratio can be calculated by substituting Equation (22) into Equation (23):

$$
\mathrm{GOR}_{\mathrm{rev}} \equiv \frac{\dot{m}_{p} h_{f g}\left(T_{0}\right)}{\dot{Q}_{\text {least }}}
$$


Reversible GOR is inversely proportional to the least heat; values are plotted in Figure 6. Maximum GOR occurs in the limit of infinitesimal recovery since the least heat is minimized as $r \rightarrow 0$. In addition to solar temperature, the limit of GOR as temperature approaches infinity is included in the figure as well.

Figure 6. Maximum gained output ratio (GOR) for desalination processes with various temperatures of heat input. Feed water is at $T_{0}=25^{\circ} \mathrm{C}$ and $y_{f}=35 \mathrm{~g} / \mathrm{kg}$.

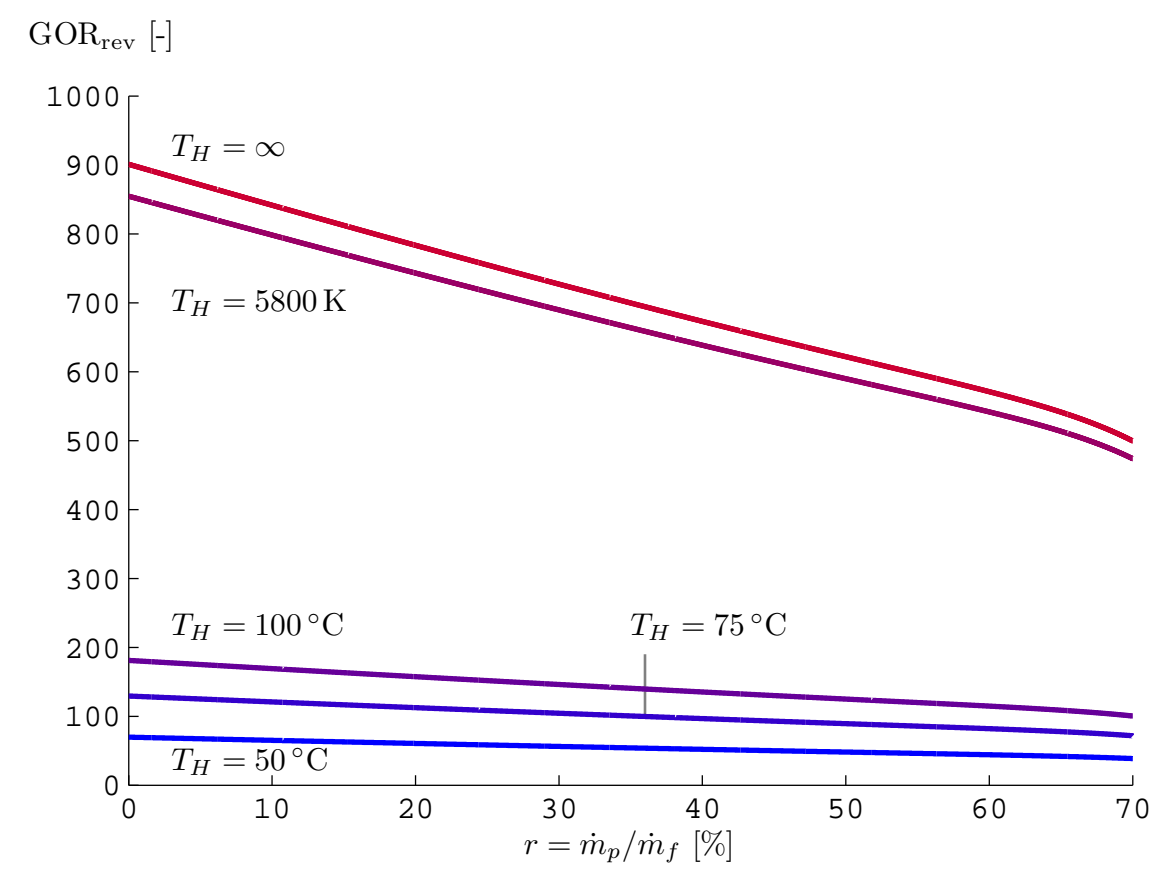

If the heat addition does not occur at a uniform temperature, then the summation in Equation (10) should be replaced with:

$$
\dot{Q}=\int\left(1-\frac{T_{0}}{T}\right) \delta \dot{Q}
$$

\section{Least Chemical Energy (Fuel) of Separation}

In some chemical separators, chemical energy is the only form of energy input, as shown in Figure 7. In this case, Equation (10) reduces to:

$$
\underbrace{\sum_{\text {in }- \text { out }} \dot{N} \bar{\xi}\left(T, p, N_{i}\right)}_{\text {fuel and exhaust streams }}=\dot{\Xi}_{\text {least }}=\underbrace{\sum_{\text {out-in }} \dot{N} \bar{g}\left(T_{0}, p_{0}, N_{i}\right)}_{\text {process streams }}
$$

Since exergy includes mechanical, thermal, and chemical components, the chemical energy component must be isolated in order to calculate the least chemical energy of separation. Therefore, the fuel is assumed to enter the system at the RDS even though some fuels are inherently not at the RDS (e.g., CNG and LNG). While it is possible to calculate the least amount of fuel needed for fuels not at the RDS, the thermal and mechanical exergy should be accounted for as well. The calculations in this paper focus purely on chemical exergy. The LHS of Equation (26) may be expanded in terms of the chemical 
potential of each species within each stream. Further, the LHS of the equation represents the net chemical energy input,

$$
\text { Net chemical energy input }=\dot{\Xi}_{\text {in }}=\underbrace{\sum_{\text {in-out }} \dot{N} \bar{\xi}\left(T_{0}, p_{0}, N_{i}\right)}_{\text {fuel and exhaust streams }}
$$

In order to determine the least amount of fuel required for a chemical separation process, the above equation must be evaluated in the context of specific situations. In the following sections, three different cases are considered.

Figure 7. A control volume for an arbitrary black box chemical separator when fuel is the only form of energy input.

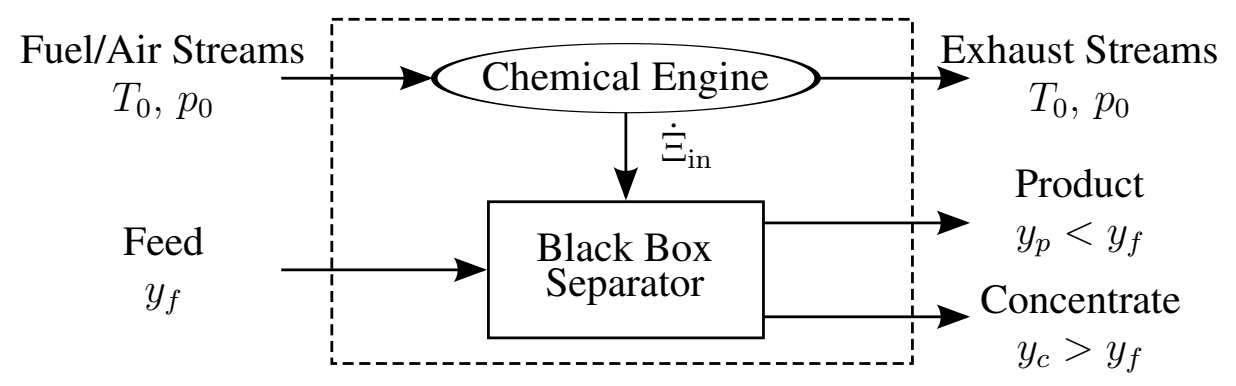

\subsection{Combustion}

Bejan [16] and Moran [35] analyzed the exergy value of fuels in detail. The maximum amount of energy that can be extracted from a fuel is the amount of work that is extracted through complete combustion when the reactants and products enter and leave the system at the TDS with the fuel entering at the RDS (see Bejan [16] [Figure 7.16 and Equation (7.133)]). As an example, for the following reaction

$$
\mathrm{C}_{\alpha} \mathrm{H}_{\beta}+\left(\alpha+\frac{\beta}{4}\right) \mathrm{O}_{2} \longrightarrow \alpha \mathrm{CO}_{2}+\frac{\beta}{2} \mathrm{H}_{2} \mathrm{O}_{\text {vapor }}
$$

the maximum amount of energy extractable (i.e., exergy) is equal to the change in the chemical potential from the reactants at the restricted dead state to the products at the total dead state:

$$
\begin{aligned}
\bar{\xi}_{\mathrm{C}_{\alpha} \mathrm{H}_{\beta}} & =\mu_{\mathrm{C}_{\alpha} \mathrm{H}_{\beta}}+\left(\alpha+\frac{\beta}{4}\right) \mu_{\mathrm{O}_{2}}-\alpha \mu_{\mathrm{CO}_{2}}-\frac{\beta}{2} \mu_{\mathrm{H}_{2} \mathrm{O}, \text { vapor }} \\
& =-\Delta G_{r}^{\circ}\left(T_{0}, p_{0}\right)+R T_{0} \ln \frac{x_{\mathrm{O}_{2}}^{\alpha+\beta / 4}}{x_{\mathrm{CO}_{2}}^{\alpha} x_{\mathrm{H}_{2} \mathrm{O}}^{\beta / 2}}
\end{aligned}
$$

where the standard state Gibbs energy of reaction for the fuel is given as

$$
\begin{aligned}
\Delta G_{r}^{\circ}= & \alpha \mu_{\mathrm{CO}_{2}}^{\circ}\left(T_{0}, p_{0}\right)+\frac{\beta}{2} \mu_{\mathrm{H}_{2} \mathrm{O}}^{\circ}\left(T_{0}, p_{0}\right) \\
& -\left[\mu_{\mathrm{C}_{\alpha} \mathrm{H}_{\beta}}^{\circ}\left(T_{0}, p_{0}\right)+\left(\alpha+\frac{\beta}{4}\right) \mu_{\mathrm{O}_{2}}^{\circ}\left(T_{0}, p_{0}\right)\right]
\end{aligned}
$$

Exergy values for select fuels, evaluated using Equation (30), are provided in Table 1 [16]. 
Table 1. Chemical exergy of select fuels at $T_{0}=25^{\circ} \mathrm{C}$ and $p_{0}=1 \mathrm{~atm}$.

\begin{tabular}{lccc}
\hline Fuel (Phase) & $\boldsymbol{M}_{\text {fuel }}[\mathbf{k g} / \mathbf{m o l}]$ & $\overline{\boldsymbol{\xi}}_{\text {fuel }}[\mathbf{k J} / \mathbf{m o l}]$ & $\boldsymbol{\xi}_{\text {fuel }}[\mathbf{M J} / \mathbf{k g}]$ \\
\hline Hydrogen $(\mathrm{g}), \mathrm{H}_{2}$ & 0.00201588 & 235.2 & 116.6736 \\
Carbon (s), C & 0.01201070 & 410.5 & 34.1779 \\
Methane (g), $\mathrm{CH}_{4}$ & 0.01604246 & 830.2 & 51.7502 \\
Propane (g), $\mathrm{C}_{3} \mathrm{H}_{8}$ & 0.04409562 & 2149.0 & 48.7350 \\
Octane (l), $\mathrm{C}_{8} \mathrm{H}_{18}$ & 0.11422852 & 5408.7 & 47.3498 \\
\hline
\end{tabular}

The total exergy provided by a given mass of fuel is therefore:

$$
\Delta \dot{\Xi}_{\text {in }}=\frac{\dot{m}_{\text {fuel }}}{M_{\text {fuel }}} \Delta \bar{\xi}_{\mathrm{C}_{\alpha} \mathrm{H}_{\beta}}
$$

Therefore, the least fuel required to separate water is:

$$
\frac{\dot{m}_{\text {fuel,least }}}{\dot{m}_{p}}=\frac{\left(g_{p}-g_{c}\right)-\frac{1}{r}\left(g_{f}-g_{c}\right)}{\bar{\xi}_{\text {fuel }}} M_{\text {fuel }}
$$

The least amount of fuel required for hydrogen gas, carbon, methane gas, propane gas, and octane liquid is shown in Figure 8. As expected, those fuels with the highest energy density result in the lowest fuel requirements.

Figure 8. Least amount of fuel needed when using combustion as a function of fuel type and recovery ratio. Feed water is at $T_{0}=25^{\circ} \mathrm{C}$ and $y_{f}=35 \mathrm{~g} / \mathrm{kg}$.

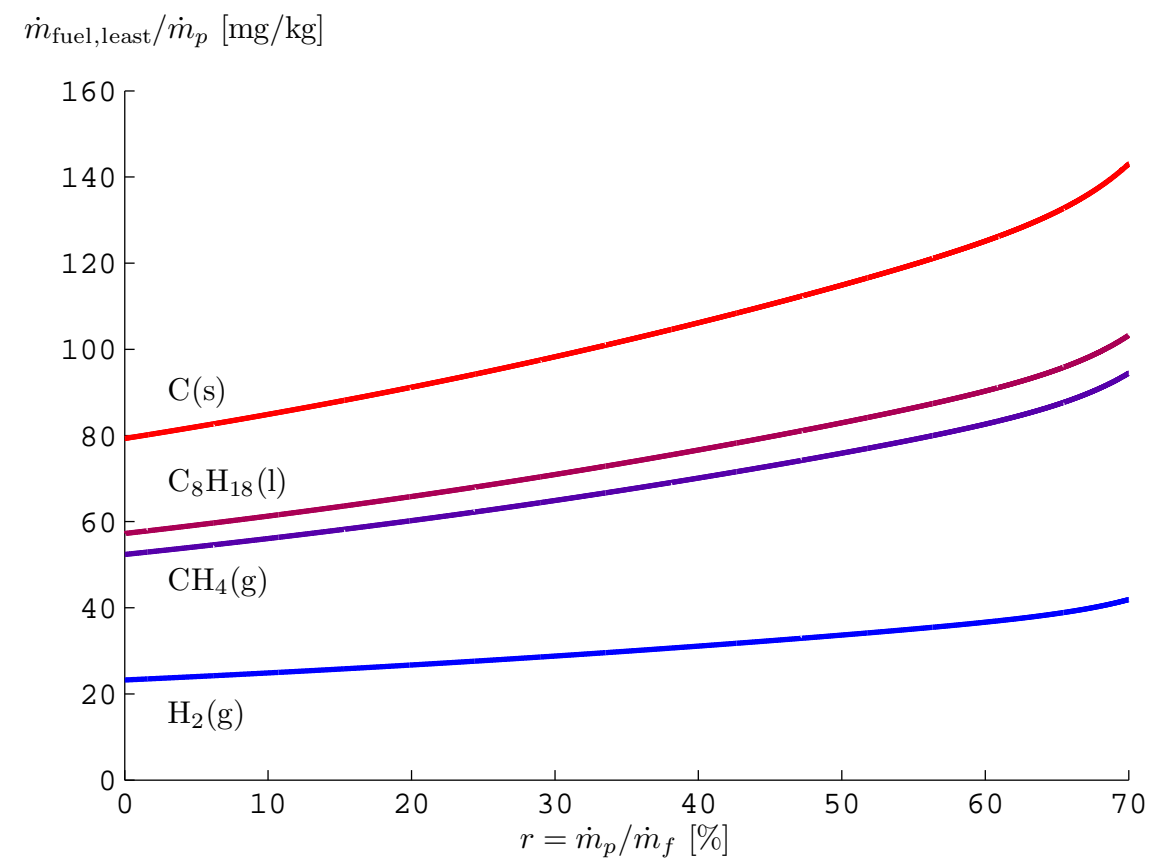




\subsection{Chemical Disequilibrium}

While combustion of fuel is the most common way to extract chemical energy, other means are possible. For example, a given solution could be internally at disequilibrium with respect to all possible internal chemical reactions. As the solution runs down to equilibrium, energy may be released to the surroundings if the reactions are exothermic. This energy could be captured and used to power a chemical separation process. Consider a system that is powered using this energy release as the solution comes to chemical equilibrium with respect to all possible internal reactions. For this case, the initial stream at disequilibrium is referred to as the "fuel", and the stream once arriving at internal chemical equilibrium is referred to as the "exhaust." No mass exchange occurs between the fuel and the environment or any of the process streams. Since this system does not allow for mass transfer with the environment (the exhaust leaves at the RDS), the exergy of the fuel and exhaust streams reduces to the Gibbs Free energy:

$$
\dot{\Xi}_{\text {in }}=\underbrace{\sum_{\text {in-out }} \dot{N} \bar{g}\left(T_{0}, p_{0}, N_{i}\right)}_{\text {fuel and exhaust streams }}
$$

For a given stream, the flow Gibbs free energy is written as:

$$
\dot{G}=\dot{N} \bar{g}=\dot{N} \sum_{i=1}^{n} x_{i} \mu_{i}=\sum_{i=1}^{n} \dot{n}_{i} \mu_{i}
$$

where

$$
\mu_{i}=\mu_{i}^{\circ}+R T \ln a_{i}
$$

Therefore, the net chemical energy input to the system is:

$$
\dot{\Xi}_{\text {in }}=\sum_{\text {in }- \text { out }}\left(\sum_{i=1}^{n}\left(\dot{n}_{i} \mu_{i}\right)\right)
$$

Finally, if it is assumed that there is a single fuel stream (includes fuel and air) and a single exhaust stream (reaction products and remaining reactants), then

$$
\dot{\Xi}_{\text {in }}=\sum_{\text {fuel }} \dot{n}_{i} \mu_{i}-\sum_{\text {exhaust }} \dot{n}_{i} \mu_{i}
$$

Now that the net chemical energy input has been rewritten in a more useful form, the amount of energy input to the system from several chemical processes is considered. For a single chemical reaction of the form:

$$
a \mathrm{~A}+b \mathrm{~B} \rightleftharpoons c \mathrm{C}+d \mathrm{D}
$$

the Gibbs free energy of reaction, $\Delta G_{r}$ is given by

$$
\Delta G_{r}=c \mu_{\mathrm{C}}+d \mu_{\mathrm{D}}-a \mu_{\mathrm{A}}-b \mu_{\mathrm{B}}
$$

$\Delta G_{r}$ represents the change in Gibbs free energy of the system as a result of a differential advancement of the chemical reaction. That is,

$$
\Delta G_{r}=\frac{\mathrm{d} G}{\mathrm{~d} \zeta} \quad \text { where } \mathrm{d} \zeta=\frac{\mathrm{d} n_{i}}{\nu_{i}}
$$


where $\zeta$ is the reaction coordinate, $n_{i}$ is the moles of species $i$, and $\nu_{i}$ is the stoichiometric coefficient of species $i$. The reaction coordinate is positive for products and negative for reactants. Substituting Equation (36) into Equation (40),

$$
\begin{aligned}
\Delta G_{r} & =\left(c \mu_{\mathrm{C}}^{\circ}+d \mu_{\mathrm{D}}^{\circ}-a \mu_{\mathrm{A}}^{\circ}-b \mu_{\mathrm{B}}^{\circ}\right)+R T \ln \frac{a_{\mathrm{C}}^{c} a_{\mathrm{D}}^{d}}{a_{\mathrm{A}}^{a} a_{\mathrm{B}}^{b}} \\
& =\Delta G_{r}^{\circ}+R T \ln Q
\end{aligned}
$$

where $Q$ is the reaction quotient. These equations may be generalized to account for more complex reactions than those of the form indicated by Equation (39):

$$
\Delta G_{r}=\sum_{i=1}^{n} \nu_{i} \mu_{i} \quad \Delta G_{r}^{\circ}=\sum_{i=1}^{n} \nu_{i} \mu_{i}^{\circ} \quad Q=\prod_{i=1}^{n} a_{i}^{\nu_{i}}
$$

At equilibrium, the change in Gibbs free energy is zero and the reaction quotient, $Q$, is equal to the equilibrium coefficient:

$$
\Delta G_{r}^{\circ}=-R T \ln K_{\mathrm{eq}}
$$

Therefore,

$$
\Delta G_{r}=-R T \ln K_{\mathrm{eq}}+R T \ln Q=R T \ln \frac{Q}{K_{\mathrm{eq}}}
$$

Equation (41) is separated and integrated from zero reaction progress to equilibrium $\left(\zeta=0 \rightarrow \zeta^{*}\right)$ :

$$
\dot{\Xi}_{\text {in }}=-\frac{\dot{m}_{\text {fuel }}}{M_{\text {fuel }}} \int_{0}^{\zeta^{*}} \Delta G_{r} \mathrm{~d} \zeta=-\frac{\dot{m}_{\text {fuel }}}{M_{\text {fuel }}} \int_{0}^{\zeta^{*}} R T \ln \frac{\prod_{i=1}^{n} a_{i}^{\nu_{i}}(\zeta)}{K_{\text {eq }}} \mathrm{d} \zeta
$$

Note that the activity of each component, and therefore the reaction quotient and the Gibbs free energy of reaction, are all functions of the reaction progress making the previous equation non-trivial to evaluate for complex reactions. While the theory is the same for multiple-reaction systems, the coupling and nonlinearity of the reactions greatly complicates the calculation.

By convention, $\Delta G_{r}$ is written per mole of the primary reactant. Therefore, the above equation is multiplied by the number of moles of fuel to determine the total energy released in the chemical reaction. Combining Equations (15), (26) and (46) gives the least mass of primary reactant needed to drive a separation process using the energy released in the equilibration of chemical species:

$$
\frac{\dot{m}_{\text {fuel,least }}}{\dot{m}_{p}}=-\frac{\left(g_{p}-g_{c}\right)-\frac{1}{r}\left(g_{f}-g_{c}\right)}{R T \int_{0}^{\zeta^{*}} \ln \frac{\prod_{i=1}^{n} a_{i}^{\nu i}(\zeta)}{K_{\text {eq }}} \mathrm{d} \zeta} M_{\text {fuel }}
$$

Equation (47) is now evaluated for a simplified case in which the energy of solvation released when a salt of the form CA is dissolved in water is used as the driver for the chemical separation process. Equation (39) reduces to a simplified form for dissolution reactions:

$$
\mathrm{CA} \rightleftharpoons \nu_{+} \mathrm{C}^{z_{+}}+\nu_{-} \mathrm{A}^{z_{-}}
$$

Activity for each of the dissolved species is written as the product of the molal activity coefficient and the molality: $a_{i}=\gamma_{i} m_{i}$ [28-30]. Activity of the pure salt, CA, is equal to one by definition. Using the definition for reaction progress given in Equation (41), the molality of each of the ions is found to be 
the product of the stoichiometric coefficient for that ion and the reaction coordinate: $\nu_{i} \zeta$. Therefore, the activities of $\mathrm{CA}, \mathrm{C}^{z_{+}}$, and $\mathrm{A}^{z_{-}}$, expressed in terms of $\zeta$, are:

$$
a_{\mathrm{CA}}=1, \quad a_{\mathrm{C}^{z_{+}}}=\gamma_{+} \nu_{+} \zeta, \quad a_{\mathrm{A}^{z_{-}}}=\gamma_{-} \nu_{-} \zeta
$$

Substituting Equation (49) into Equation (40), the Gibbs free energy of this reaction is:

$$
\Delta G_{r}=R T \ln \frac{Q(\zeta)}{K_{\mathrm{sp}}}=R T \ln \frac{\left(\gamma_{+}^{\nu_{+}} \gamma_{-}^{\nu_{-}}\right)\left(\nu_{+}^{\nu_{+}} \nu_{-}^{\nu_{-}}\right) \zeta^{\nu_{+}+\nu_{-}}}{K_{\mathrm{sp}}}
$$

Substitution into Equation (46) and assuming ideal solution behavior to simplify the calculation ( $\gamma$ is a complex function of $\zeta$ ) gives:

$$
\dot{\Xi}_{\text {in }}=-\frac{\dot{m}_{\text {salt }}}{M_{\text {salt }}} R T \zeta^{*}\left[\ln \left(\frac{\nu_{+}^{\nu_{+}} \nu_{-}^{\nu_{-}}}{K_{\mathrm{sp}}} \zeta^{* \nu_{+}+\nu_{-}}\right)-\left(\nu_{+}+\nu_{-}\right)\right]
$$

The equilibrium condition is found by setting $\Delta G_{r}=0$ and solving for Equation (50) for $\zeta$ :

$$
\zeta^{*}=\left[\frac{K_{\mathrm{sp}}}{\nu_{+}^{\nu_{+}} \nu_{-}^{\nu_{-}}}\right]^{\frac{1}{\nu_{+}+\nu_{-}}}
$$

Substituting into $\dot{\Xi}_{\text {in }}$ gives

$$
\dot{\Xi}_{\text {in }}=\frac{\dot{m}_{\text {salt }}}{M_{\text {salt }}} R T\left(\nu_{+}+\nu_{-}\right)\left[\frac{K_{\mathrm{sp}}}{\nu_{+}^{\nu_{+}} \nu_{-}^{\nu_{-}}}\right]^{\frac{1}{\nu_{+}+\nu_{-}}}
$$

Finally, the least amount of salt dissolution required is:

$$
\frac{\dot{m}_{\text {salt,least }}}{\dot{m}_{p}}=\frac{\left(g_{p}-g_{c}\right)-\frac{1}{r}\left(g_{f}-g_{c}\right)}{R T\left(\nu_{+}+\nu_{-}\right)\left[\frac{K_{\mathrm{sp}}}{\nu_{+}^{\nu+} \nu_{-}}\right]^{1 /\left(\nu_{+}+\nu_{-}\right)}} M_{\text {salt }}
$$

Figure 9 shows the amount of salt needed to drive a separation process when $\mathrm{CaSO}_{4}$ and $\mathrm{Ag}_{2} \mathrm{SO}_{4}$ are used. From the results of Figure 9, it is clear that using the energy of solvation for a salt to chemically separate another electrolyte solution is not a practical process since it would require very large quantities of both salt and water and would be unrealistically expensive. In the case of $\mathrm{Ag}_{2} \mathrm{SO}_{4}$, at the minimum, it requires approximately $7 \mathrm{~kg}$ for every kilogram of water produced while nearly $15 \mathrm{~kg}$ of $\mathrm{CaSO}_{4}$ is required to produce a kilogram of water. This methodology is given not to suggest that dissolution reactions are a practical way to extract energy, but rather to illustrate a method for evaluating the energy release in an arbitrary chemical reaction. 
Figure 9. Least amount of salt needed when letting a salt dissociate to equilibrium as a function of recovery ratio for $\mathrm{CaSO}_{4}$ and $\mathrm{AgSO}_{4}$. Feed water is at $T_{0}=25^{\circ} \mathrm{C}$ and $y_{f}=35 \mathrm{~g} / \mathrm{kg}$.

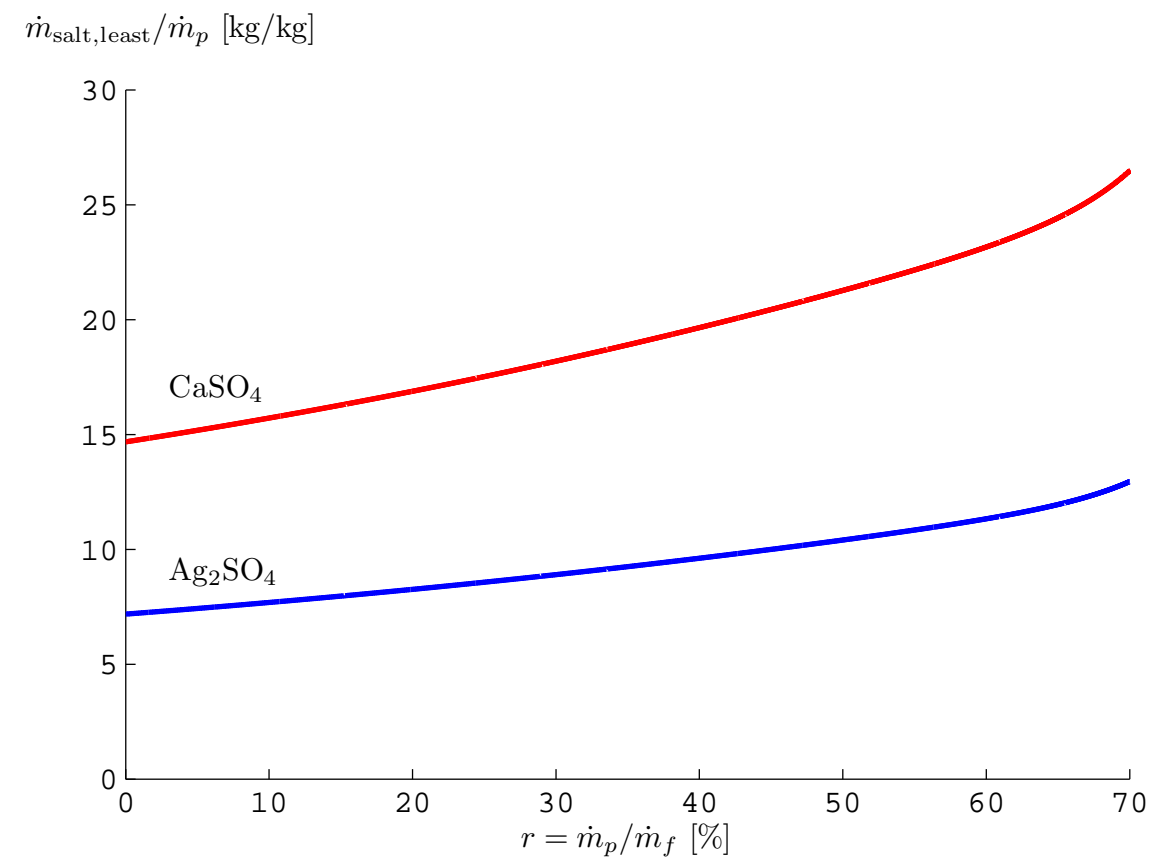

\subsection{Electrochemical Reactions}

Consider a system that is powered by an oxidation-reduction (REDOX) reaction in a fuel cell [36,37]. As with chemical equilibration reactions, the Gibbs free energy of reaction is:

$$
\Delta G_{r}=\sum_{i} \nu_{i} \mu_{i}=\Delta G_{r}^{\circ}+R T \ln Q
$$

The electromotive force (voltage) generated by a REDOX reaction is found by noting that $\Delta G_{r}=-n_{e} F E$ where $n_{e}$ is the number of electrons transferred per mole of reactant and $F$ is Faraday's constant. Therefore,

$$
\begin{aligned}
-\frac{\Delta G_{r}}{n_{e} F} & =-\frac{\Delta G_{r}^{\circ}}{n_{e} F}-\frac{R T}{n_{e} F} \ln Q \\
E & =E^{\circ}-\frac{R T}{n_{e} F} \ln Q
\end{aligned}
$$

Equation (57) is known as the Nernst equation. At $25^{\circ} \mathrm{C}$, it is equal to:

$$
E=E^{\circ}-\frac{0.059}{n_{e}} \log Q
$$

The power drawn from an electrochemical cell is found by multiplying the current drawn by the voltage. The current is the charge drawn per time,

$$
I=\frac{\text { charge }}{\text { time }}=\frac{n_{e} e N_{a} N}{t}=\frac{n_{e} F N}{t}
$$


where $n_{e}$ is the number of electrons per mole of reactant, $e$ is the electron charge, $F=e N_{a}$, and $N$ is the number of moles of reactant.

$$
\dot{\Xi}_{\text {in }}=\sum_{\text {reactants }} \dot{n}_{i} \mu_{i}-\sum_{\text {products }} \dot{n}_{i} \mu_{i}=-\dot{N} \sum_{i} \nu_{i} \mu_{i}=-\dot{N} \Delta G_{r}=-\frac{N}{t} n_{e} F \frac{\Delta G_{r}}{-n_{e} F}=I E
$$

Therefore,

$$
\dot{\Xi}_{\text {in }}=I E=\dot{N} n_{e} F\left(E^{\circ}-\frac{R T}{n_{e} F} \ln Q\right)
$$

Note that for an electrochemical reaction, the change in Gibbs free energy of the reactants minus the products is equal to the current times the voltage difference (power), which is exactly equal to the power associated with electrical work.

If the products of the fuel cell reaction are allowed to come to chemical equilibrium with the environment, then the reaction quotient will be a function of the activities of the products and reactants at ambient conditions. Under such conditions, Equation (61) reduces to the exergetic value of fuels as seen in the combustion case and Equation (33) can be used to evaluate the least mass of fuel required when driving a separation process using a fuel cell. Therefore, Figure 8 also represents the least amount of fuel needed to drive a separation process when the fuel is used in a fuel cell. This result is expected since the exergetic value of a fuel is independent of the manner in which the chemical energy is extracted.

\subsection{Limitations}

In order to use this methodology as described in the preceding sections, it is essential that the process streams do not exchange mass with the fuel and exhaust streams. If mass exchange were allowed between the process streams and the fuel and exhaust streams, then it would be impossible to clearly define the change in Gibbs free energy of the process streams and the change in exergy of the fuel/exhaust streams as shown in Equation (10), since conservation of mass over these summations would not be maintained. For systems in which there is mass exchange between the process streams and the fuel/exhaust streams, some care is needed in how each of the streams are classified. In order to illustrate how to apply this methodology to such systems, a work-driven system with a chemical energy assist stream is considered in the following section.

\section{Least Work of Separation for a Separator with a Chemical Energy Assist Stream}

Some chemical separation processes use an additional process stream in order to assist the overall separation process and reduce the amount of energy input required. One such process is RO coupled with an FO-based energy recovery device (ERD), as shown in Figure 10 [12,38,39]. In this system, high salinity brine from the RO module is passed through an FO module in which $\mathrm{H}_{2} \mathrm{O}$ from a chemical energy assist stream (denoted $a$ ) of a different chemical composition is transferred through the FO membrane from the assist stream to the concentrated brine. The additional $\mathrm{H}_{2} \mathrm{O}$ transferred to the brine stream allows for a higher volumetric flow rate through the pressure exchanger, thus reducing the amount of feed that must be pressurized through the high pressure pump prior to entering the RO module and reducing the amount of electrical work that must be provided to the system [13]. 
Figure 10. Schematic diagram of a typical single stage reverse osmosis system with a forward osmosis and pressure exchanger energy recovery devices.

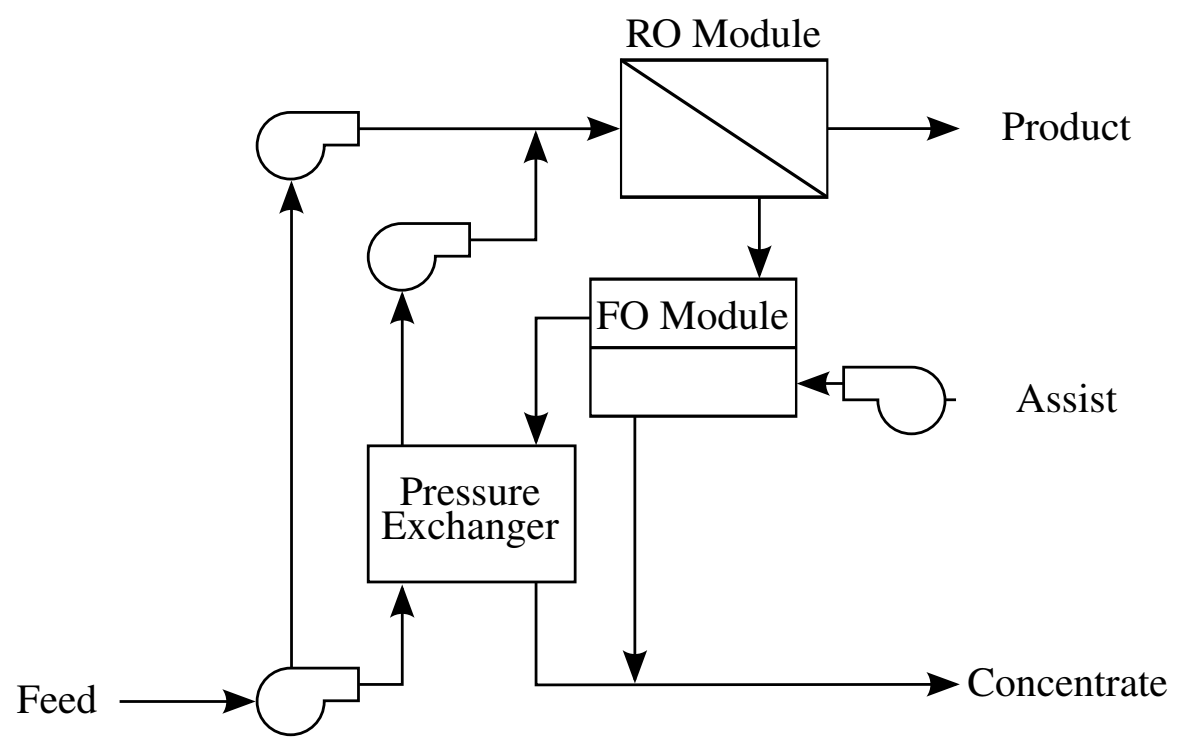

This RO-FO system, and any other type of chemical separation process that relies on an additional process stream, can be abstracted to a variation of the simple black box separator model that has been used in Section 3. In this abstraction, the ERD is called a salinity gradient engine (SGE) to account for the fact that the net chemical energy difference between the feed and the assist might be greater than the energy required for the separation process, resulting in positive work output from the system. Note that the FO module and pressure exchanger shown in Figure 10 are only capable of energy recovery, not power production. However, there are SGEs [e.g., pressure retarded osmosis (PRO) and reverse electrodialysis (RED)] that are capable of net power production [40]. A control volume drawn around such a system reduces to a separator with an SGE, four process streams (feed, product, concentrate, and assist), a work input, and heat transfer with the environment (Figure 11). Even though the assist stream is used for providing additional energy into the system, the assist stream cannot be considered a "fuel" stream since part of it is blended into the product stream. Therefore, it is counted as an additional process stream.

Figure 11. A control volume for an arbitrary black box chemical separator powered by work and a salinity gradient engine.

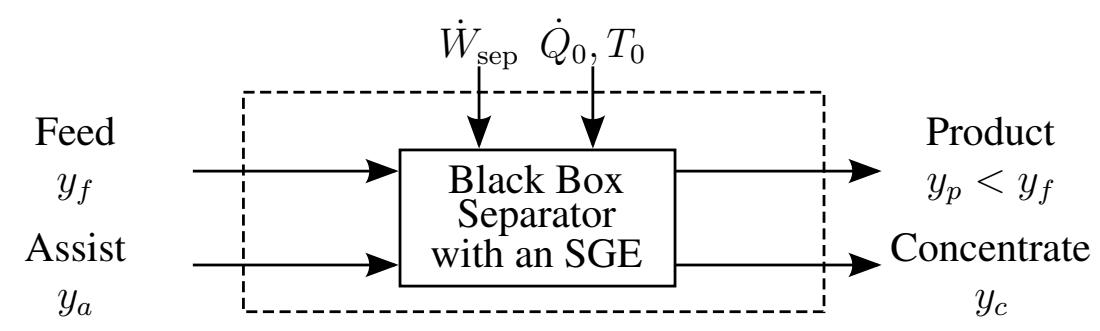

Equation (11) is expanded in terms of all four process streams:

$$
\dot{\Xi}_{\text {least }}=\sum_{\text {out-in }} \dot{m} g\left(T_{0}, p_{0}, N_{i}\right)=\dot{m}_{p} g_{p}+\dot{m}_{c} g_{c}-\dot{m}_{f} g_{f}-\dot{m}_{a} g_{a}
$$


Because there are two material input streams, two parameters are required to fully define the mass flow rates of each of the stream. The first parameter is the recovery ratio, as defined in Equation (13). The second is the ratio of the mass flow rate of the energy recovery stream to the mass flow rate of the feed stream:

$$
r_{a} \equiv \frac{\dot{m}_{a}}{\dot{m}_{f}}=\frac{\text { mass flow rate of energy recovery stream }}{\text { mass flow rate of feed }}
$$

Conservation of mass for both the solution and the salts is written:

$$
\begin{aligned}
\dot{m}_{f}+\dot{m}_{a} & =\dot{m}_{p}+\dot{m}_{c} \\
\dot{m}_{f} y_{f}+\dot{m}_{a} y_{a} & =\dot{m}_{p} y_{p}+\dot{m}_{c} y_{c}
\end{aligned}
$$

Equation (62) can be rewritten in terms of the two mass flow rate ratios by combining Equations (13), (63) and (64). Normalizing by the product flow rate gives:

$$
\frac{\dot{W}_{\text {least }}}{\dot{m}_{p}}=\left(g_{p}-g_{c}\right)-\frac{1}{r}\left(g_{f}-g_{c}\right)-\frac{r_{a}}{r}\left(g_{a}-g_{c}\right)
$$

Provided the salinities of the product, feed, and energy recovery stream are known, the salinity of the concentrate may be evaluated by combining Equations (13) and (63) to (65):

$$
y_{c}=\frac{y_{f}+r_{a} y_{a}-r y_{p}}{1+r_{a}-r}
$$

Note that when $r_{a}=0$, Equations (62), (66) and (67) reduce to Equations (12), (15) and (17). Equation (66) can be equated to Equation (10) to express the generalized least energy of separation for a black box separator that includes an SGE and an assist stream. Additionally, all of the conclusions found from the previous sections can be applied to systems of this nature. For brevity, only work input will be considered for the example in this section.

Equation (66) is a function of the salinity of each of the four streams, the recovery ratio, the ratio of the mass flow rates of the assist to the feed, temperature, and pressure. For standard seawater at ambient conditions and pure product water, the equation is still a function of $r, r_{a}$, and $y_{a}$.

First, consider the effect of varying the mass flow rate of the assist stream while holding the salinity of the assist fixed and equal to that of the feed (i.e., $y_{a}=y_{f}=35 \mathrm{~g} / \mathrm{kg}$ ). Additionally, for the sake of simplicity, it is assumed that the assist stream has the same ionic composition as the feed water and that seawater properties may be used [30,33]. Since the assist has the same salinity (and composition) as the feed water, the total feed to the system can be considered the sum of $\dot{m}_{f}$ and $\dot{m}_{a}$ while the product flow rate is fixed. Therefore, as $r_{a}$ increases, the least work of separation will decrease, as is observed in Figure 12. In the limit as $r_{a} \rightarrow \infty$, the least work of separation approaches the minimum least work of separation, regardless of recovery ratio, since this situation corresponds to the case of infinitesimal recovery [ $c f$., Equation (18)].

The case of varying the salinity of the assist while holding $r_{a}$ fixed results in more interesting (and useful) observations. To examine the effect of varying assist salinity, the flow rate of the assist is held fixed and equal to the flow rate of the feed (i.e., $\dot{m}_{a}=\dot{m}_{f}$, or $r_{a}=1$ ). The least work of separation under these conditions with the salinity of the assist varying from 25 to $45 \mathrm{~g} / \mathrm{kg}$ is shown in Figure 13 . Additionally, the least work without the $\operatorname{SGE}\left(\right.$ i.e., $r_{a}=0$ ) is also shown in black for reference. Several 
important observations can be made from Figure 13. First, at higher recovery ratios, the least work of separation for the system with an SGE decreases with decreasing assist salinity. In all cases, the least work is less than the base case without an SGE since the process is effectively treating a greater amount of feed at a lower recovery ratio than the base system. Second, for all assist streams that are at a salinity that is different than the feed salinity (both greater and less than), as recovery ratio approaches zero, the least work approaches negative infinity. This occurs because the difference in salinity between the assist and the feed represents a chemical energy potential that can be used to drive the separation process.

Figure 12. Least work of separation for a black box separator with a salinity gradient engine as a function of feed salinity, recovery ratio, and ratio of the energy recovery stream to the feed. Feed water is at $T_{0}=25^{\circ} \mathrm{C}$ and $y_{f}=35 \mathrm{~g} / \mathrm{kg}$.

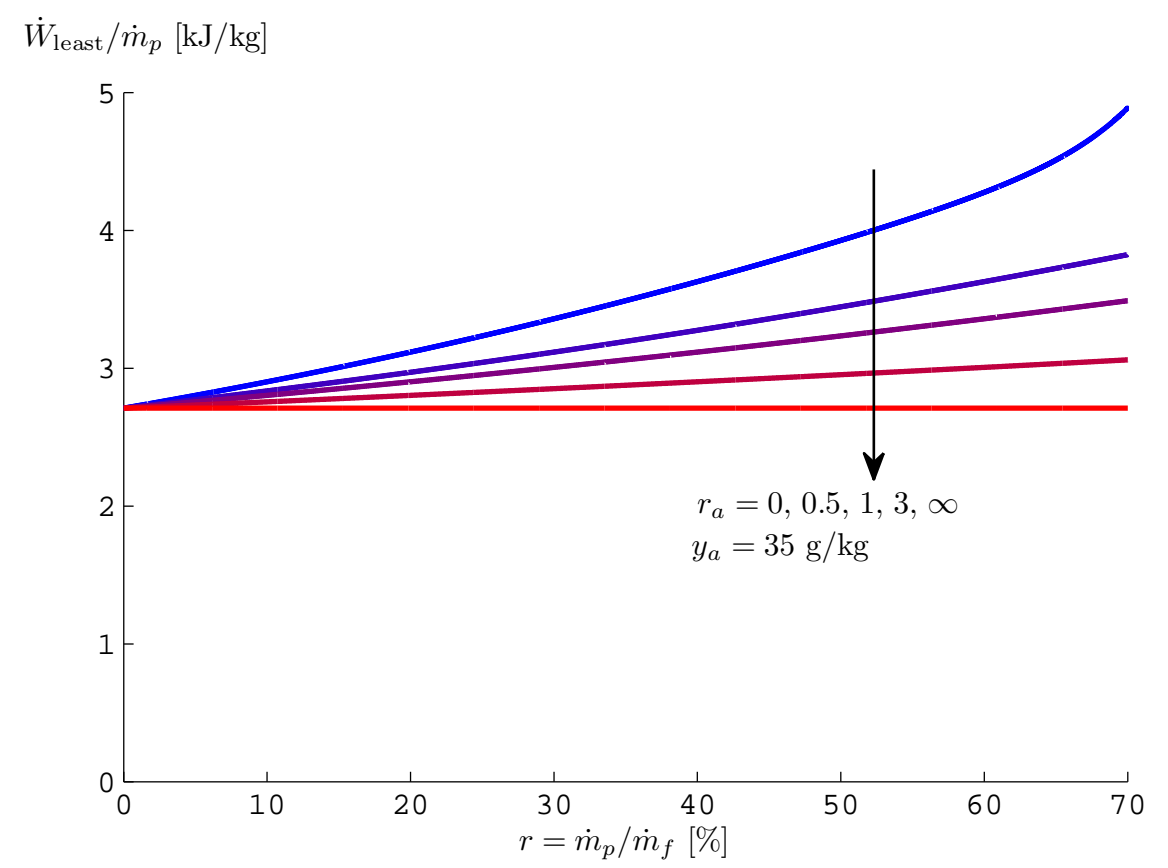

As the recovery ratio approaches zero, however, the chemical energy potential exceeds the work requirements, and therefore, the system becomes a net work producing system with negative values of work of separation. The tendency toward infinite work production is an artifact caused by plotting least work divided by product flow rate when product flow rate approaches zero. This apparent singularity is not observed in the base case of no assist $\left(r_{a}=0 \mathrm{~kg} / \mathrm{kg}\right)$ since the rate at which the least work approaches zero is faster than the rate at which $\dot{m}_{p}$ approaches zero. However, in the present case of a system with an assist, the least work is a function of both the amount of energy required to produce $\dot{m}_{p}$ and the amount of energy that can be produced as a result of the chemical energy difference between the feed stream and the assist. While the work required to produce $\dot{m}_{p}$ approaches zero in the limit of infinitesimal recovery, the chemical energy difference between the feed and assist remains finite and therefore, the ratio of $\dot{W}_{\text {least }} / \dot{m}_{p}$ tends toward negative infinity. Finally, for assists that are at a greater salinity than the feed, there is a recovery ratio at which the least work requirement is exactly equal to the least work of the system without an SGE that corresponds to the point at which the least work curves are tangent to 
the base case least work. For recovery ratios near this critical point, the use of an SGE does not lead to significant energy savings.

Figure 13. Least work of separation for a black box separator with a salinity gradient engine as a function of feed salinity, recovery ratio, and salinity of the energy recovery stream. Feed water is at $T_{0}=25^{\circ} \mathrm{C}$ and $y_{f}=35 \mathrm{~g} / \mathrm{kg}$.

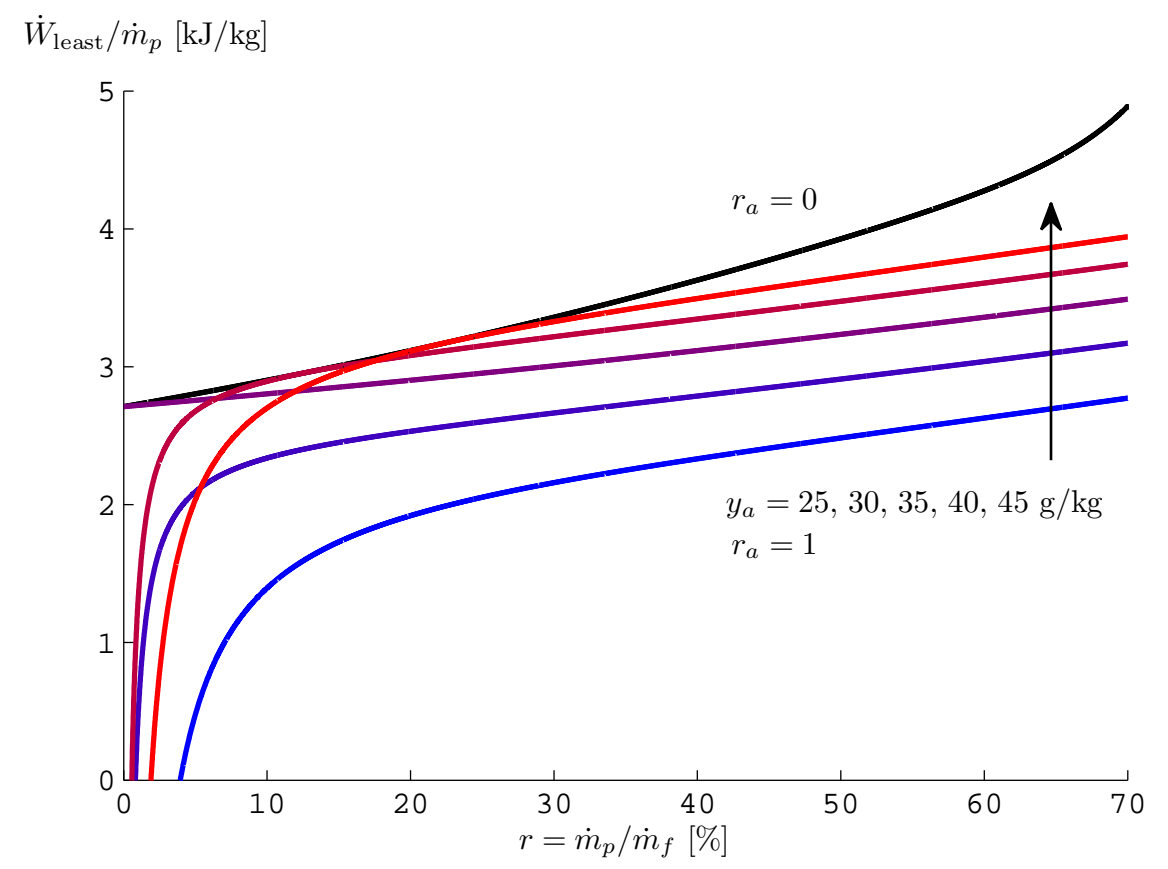

Introduction of an additional material stream that mixes with the process streams changes the overall system performance characteristics. As shown in this example, under certain conditions, it is possible for the least exergy of separation to be negative when there is an additional energy carrying stream provided to the system. When the least exergy is negative, the system is work producing and the magnitude of $\dot{W}_{\text {least }}$ represents the maximum amount of work that can be produced from the four streams under reversible operation (e.g., the reversible work produced by an osmotic power plant). It is not possible for least work to ever be negative if the only process streams are the feed, product, and concentrate, as was discussed in Sections 3 to 5.

\section{Second Law Efficiency}

Second Law (or exergetic) efficiency $\left(\eta_{I I}\right)$ is employed as a measure of the thermodynamic reversibility of a desalination system [13]. Unlike First Law efficiency, which measures the amount of an energy source that is put to use, Second Law efficiency measures the extent of irreversible losses within a system. As a result, a completely reversible system will have a Second Law efficiency of 1 even though the First Law efficiency is likely to be lower. Bejan [16] and others $[9,35]$ define the exergetic efficiency as the ratio of the exergy of the process products to the process fuel. In other words, the 
exergetic efficiency is the ratio of the useful exergy of the outputs of the process ( $\left.\dot{\Xi}_{\text {out,useful }}\right)$ to the exergy of the process inputs $\left(\dot{\Xi}_{\text {in }}\right)$ :

$$
\eta_{I I} \equiv \frac{\dot{\Xi}_{\text {out,useful }}}{\dot{\Xi}_{\text {in }}}=1-\frac{\dot{\Xi}_{\text {destroyed }}+\dot{\Xi}_{\text {lost }}}{\dot{\Xi}_{\text {in }}}
$$

The second equality in Equation (68) is valid since the useful exergy out is equal to the exergy in minus the sum of the exergy destroyed ( $\left.\dot{\Xi}_{\text {destroyed }}\right)$ and the exergy lost ( $\left.\dot{\Xi}_{\text {lost }}\right)$. Exergy destroyed represents lost available work due to irreversibilities within the system. Exergy lost represents lost available work due to discarding exergy carrying streams to the environment. Note that when the material inputs to the system are taken to be at equilibrium with the environment, $\dot{\Xi}_{\text {in }}$ equals $\dot{\Xi}_{\dot{W}_{\text {sep }}}, \dot{\Xi}_{\dot{Q}_{\text {sep }}}$, or $\dot{\Xi}_{\text {fuel }}$, depending on the energy input.

\subsection{Second Law Efficiency for a Chemical Separator}

As discussed by Mistry et al. [13], the useful output from a desalination system is the amount (mass) of purified product water that is created. Exergetically, the mass of the product water is represented by the minimum least work of separation, which is the least work of separation at infinitesimal recovery:

$$
\dot{W}_{\text {least }}^{\min } \equiv \lim _{r \rightarrow 0} \dot{W}_{\text {least }}=\lim _{r \rightarrow 0} \dot{\Xi}_{\text {least }}
$$

Similarly, the minimum least heat of separation is at infinitesimal recovery:

$$
\dot{Q}_{\text {least }}^{\min } \equiv \lim _{r \rightarrow 0} \dot{Q}_{\text {least }}=\lim _{r \rightarrow 0}\left(1-\frac{T_{0}}{T}\right)^{-1} \dot{\Xi}_{\text {least }}
$$

A new parameter called the minimum least fuel of separation may also be introduced:

$$
\dot{m}_{\text {least }}^{\min } \equiv \lim _{r \rightarrow 0} \dot{m}_{\text {least }}=\lim _{r \rightarrow 0} \xi_{\text {fuel }}^{-1} \dot{\Xi}_{\text {least }}
$$

Using the minimum least work, heat, and fuel of separation, the Second Law efficiency can be defined in three different ways:

$$
\eta_{I I}=\frac{\dot{W}_{\text {least }}^{\min }}{\dot{W}_{\mathrm{sep}}}, \quad \eta_{I I}=\frac{\dot{Q}_{\text {least }}^{\min }}{\dot{Q}_{\mathrm{sep}}}, \quad \eta_{I I}=\frac{\dot{m}_{\text {least }}^{\min }}{\dot{m}_{\mathrm{sep}}}
$$

A more general way to define Second Law efficiency is simply to use exergy:

$$
\eta_{I I}=\frac{\dot{\Xi}_{\text {least }}^{\min }}{\dot{\Xi}_{\mathrm{sep}}}
$$

Note that Equation (73) reduces to the three special cases given in Equation (72) depending on which energy inputs are used.

It is important to ensure that control volume selection is consistent for all systems being considered in order to fairly compare the Second Law performance. While Equation (73) is straightforward to evaluate for systems with only one source of energy input, some care is required when using it to evaluate systems with multiple energy inputs. First, consider the numerator, which is defined by Equation (18). The minimum least exergy of separation is fixed and is a function of the environmental temperature and 
pressure as well as the salinities of the feed, concentrate, and product streams only, regardless of the energy input.

The denominator is a little less straightforward to evaluate and is highly dependent on how the control volume is drawn. For a standalone desalination system in which some combination of work, heat, and fuel is used to power the separation process, the denominator is simply the left hand side of Equation (8):

$$
\dot{\Xi}_{\text {sep }}=\dot{W}_{\text {sep }}+\left(1-\frac{T_{0}}{T}\right) \dot{Q}_{\text {sep }}+\xi_{\text {fuel }} \dot{m}_{\text {sep }}
$$

since this represents the sum of the exergy of each of the various energy inputs provided to the desalination system. To illustrate the evaluation of Equation (73) using Equation (74), $\eta_{I I}$ is calculated for various standalone desalination systems that are driven using a combination of electrical and thermal energy input. Relevant values of $\dot{W}_{\text {sep }}, \dot{Q}_{\text {sep }}$, and other parameters for HDH [25] and FO [20] are taken from literature and the results are provided in Table 2. Note that the optimal energy requirements for $\mathrm{HDH}$ are not a strong function of feed salinity and the Second Law efficiency for HDH systems will scale approximately linearly with the minimum least work of separation, which itself is purely a function of feed salinity $[13,41]$.

Table 2. Second Law efficiency for various standalone experimental desalination systems. Values marked with $*$ are estimated. Values marked with $\dagger$ are evaluated using estimated figures. Note that $\Xi_{\text {sep }}$ is a strong function of $T_{H}$ and $\eta_{I I}$ is a strong function of $T_{H}$ and $y_{f}$.

\begin{tabular}{lcccccc}
\hline System & $\begin{array}{c}\boldsymbol{y}_{\boldsymbol{f}} \\
{[\mathbf{g} / \mathbf{k g}]}\end{array}$ & $\begin{array}{c}\dot{\boldsymbol{W}}_{\text {sep }} \\
{[\mathbf{k J} / \mathbf{k g}(\mathbf{K W h})]}\end{array}$ & $\begin{array}{c}\dot{\boldsymbol{Q}}_{\text {sep }} \\
{[\mathbf{k J} / \mathbf{k g}]}\end{array}$ & $\begin{array}{c}\boldsymbol{T}_{\boldsymbol{H}} \\
{\left[{ }^{\circ} \mathrm{C}\right]}\end{array}$ & $\begin{array}{c}\dot{\Xi}_{\text {sep }} \\
{[\mathbf{k J} / \mathbf{k g}]}\end{array}$ & $\begin{array}{c}\eta_{I I} \\
{[\%]}\end{array}$ \\
\hline HDH [25] & $35^{*}$ & $1.44(0.40)$ & $848(\mathrm{GOR}=2.6)$ & 90 & 153 & $1.8^{\dagger}$ \\
HDH (extraction) [25] & $35^{*}$ & $1.62(0.45)$ & $551(\mathrm{GOR}=4.0)$ & 90 & 100 & $2.7^{\dagger}$ \\
FO [20] & 73 & $30.6(8.50)$ & $990\left(275 \mathrm{KWh}_{t}\right)$ & $100[42]$ & 230 & 2.5 \\
\hline
\end{tabular}

Equation (74) should not be used for desalination systems in which those energy inputs (i.e., $\dot{W}_{\text {sep }}$, $\dot{Q}_{\text {sep }}$, and $\dot{m}_{\text {sep }}$ ) are not of the same form and quality as the energy inputs to the larger cogeneration system. It is essential that $\eta_{I I}$ be evaluated in terms of primary energy sources (i.e., in terms of the energy inputs to the larger system control volume, not just to the desalination plant control volume) in order to properly account for all thermodynamic losses that occur, including those in energy conversion processes such as the generation of electricity from heat. Given that many large-scale desalination processes are done in a cogeneration scheme in which some form of primary energy (typically fuel) is used to generate both electricity and desalinated water, $\eta_{I I}$ for those systems should be evaluated in terms of the primary energy input for the cogeneration system as is discussed in the following section.

\subsection{Second Law Efficiency for a Desalination System Operating as Part of a Cogeneration Plant}

Since many large-scale desalination processes are done in a cogeneration scheme, it is useful to consider the amount of additional energy that must be provided to the power plant in order to generate the required amount of heat and work to power the desalination plant. In order to do so, consider a 
cogeneration system in which a power plant is connected to a desalination plant as shown in Figure 14. In this system, a heat input $\left(\dot{Q}_{H}\right)$ is provided to a power plant. This heat input is equal to the amount of heat necessary to drive the power plant $\left(\dot{Q}_{p p}\right)$ plus the additional amount necessary to generate steam and electricity for the desalination plant $\left(\dot{Q}_{d}\right.$ to produce $\dot{Q}_{\text {sep }}$ and $\left.\dot{W}_{\text {sep }}\right)$. The power plant produces a net amount of work equal to the desired plant work production $\left(\dot{W}_{p p}\right)$ plus the amount of work necessary to drive the desalination plant $\left(\dot{W}_{\mathrm{sep}}\right)$. Note that typically, fuel, rather than heat, is the primary energy input to cogeneration systems and therefore, the analysis should be done in terms of the amount of fuel required to drive the power plant plus the additional amount of fuel required to produce the heat and work necessary to drive the desalination plant $\left(\dot{m}_{\text {fuel }}=\dot{m}_{p p}+\dot{m}_{d}\right)$. However, for simplicity and with the goal of highlighting the difference between work and heat driven systems, the control volume for this analysis is drawn under the assumption that heat, and not fuel, is transferred into the system. The effect of including the combustor is discussed briefly below.

Figure 14. The power plant converts heat input into work output, work for the desalination plant, and heat for the desalination plant. It is assumed that the power plant operates at a Second Law efficiency of $\eta_{p p}$.

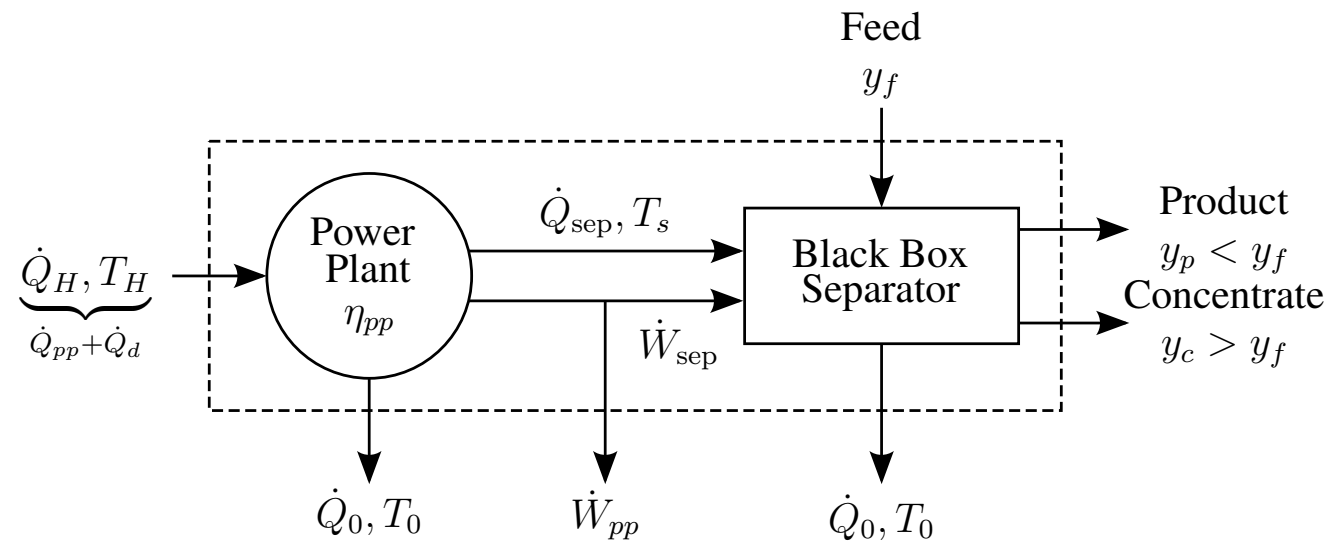

The following derivation is based on the work of El-Sayed and Silver [5]. The First and Second Laws of Thermodynamics are written about the power plant control volume:

$$
\begin{aligned}
\dot{Q}_{p p}+\dot{Q}_{d} & =\dot{Q}_{\text {sep }}+\dot{Q}_{0}+\dot{W}_{p p}+\dot{W}_{\text {sep }} \\
\dot{S}_{\text {gen }}+\frac{\dot{Q}_{p p}}{T_{H}}+\frac{\dot{Q}_{d}}{T_{H}} & =\frac{\dot{Q}_{\text {sep }}}{T_{s}}+\frac{\dot{Q}_{0}}{T_{0}}
\end{aligned}
$$

Multiplying the Second Law by $T_{0}$ and substituting into the First Law to eliminate ambient heat transfer $\left(\dot{Q}_{0}\right)$ gives:

$$
\dot{W}_{p p}+\dot{W}_{\mathrm{sep}}=\left(\dot{Q}_{p p}+\dot{Q}_{d}\right)\left(1-\frac{T_{0}}{T_{H}}\right)-\dot{Q}_{\text {sep }}\left(1-\frac{T_{0}}{T_{s}}\right)-T_{0} \dot{S}_{\text {gen }}
$$

In order to deal with the irreversibilities within the system, it is assumed that the rate of entropy generation is proportional to the amount of work produced by a reversible power plant operating within the same heat transfer loads. That is,

$$
T_{0} \dot{S}_{\text {gen }} \propto\left(\dot{W}_{p p}+\dot{W}_{\text {sep }}\right)=\left(\dot{Q}_{p p}+\dot{Q}_{d}\right)\left(1-\frac{T_{0}}{T_{H}}\right)-\dot{Q}_{\text {sep }}\left(1-\frac{T_{0}}{T_{s}}\right)
$$


Letting the constant of proportionality be $\left(1-\eta_{p p}\right)$, where $\eta_{p p}=\eta / \eta_{\text {Carnot }}$ is the Second Law efficiency of the power plant,

$$
T_{0} \dot{S}_{\text {gen }}=\left[\left(\dot{Q}_{p p}+\dot{Q}_{d}\right)\left(1-\frac{T_{0}}{T_{H}}\right)-\dot{Q}_{\text {sep }}\left(1-\frac{T_{0}}{T_{s}}\right)\right]\left(1-\eta_{p p}\right)
$$

Substituting $T_{0} \dot{S}_{\text {gen }}$ into Equation (77) gives:

$$
\dot{W}_{p p}+\dot{W}_{\mathrm{sep}}=\left(\dot{Q}_{p p}+\dot{Q}_{d}\right)\left(1-\frac{T_{0}}{T_{H}}\right) \eta_{p p}-\dot{Q}_{\text {sep }}\left(1-\frac{T_{0}}{T_{s}}\right) \eta_{p p}
$$

Since the goal is to determine how much additional heat is necessary to drive the desalination system, $\dot{Q}_{d}$ must be independent of the amount of work produced by the power plant. To do so, first consider the same power plant in which the desalination system is not operating and the power plant is producing a net output of $\dot{W}_{p p}$. Then, setting $\dot{Q}_{d}, \dot{Q}_{\text {sep }}$, and $\dot{W}_{\text {sep }}$ to zero, $\dot{Q}_{p p}$ is found to be:

$$
\dot{Q}_{p p}=\frac{\dot{W}_{p p}}{\left(1-\frac{T_{0}}{T_{H}}\right) \eta_{p p}}
$$

Substituting this back into the above equation results in $\dot{Q}_{p p}$ and $\dot{W}_{p p}$ canceling out. Solving for $\dot{Q}_{d}$,

$$
\dot{Q}_{d}=\frac{\dot{W}_{\mathrm{sep}}}{\left(1-\frac{T_{0}}{T_{H}}\right) \eta_{p p}}+\dot{Q}_{\mathrm{sep}} \frac{\left(1-\frac{T_{0}}{T_{s}}\right)}{\left(1-\frac{T_{0}}{T_{H}}\right)}
$$

In order to evaluate the Second Law efficiency of the desalination plant, one might think to use Equation (74) for the denominator in Equation (73) since it represents the energy inputs to the desalination system. While this would be correct for a standalone system, $\dot{W}_{\text {sep }}$ and $\dot{Q}_{\text {sep }}$ do not represent the true energy inputs for separation system shown in Figure 14. Instead, the energy input for the desalination system is the extra heat transfer provided to the power plant, $\dot{Q}_{d}$. Therefore, the Second Law efficiency should be evaluated based on this quantity. Substituting Equation (82) into Equation (73) gives:

$$
\eta_{I I}=\frac{\dot{\Xi}_{\text {least }}^{\min }}{\dot{\Xi}_{\text {sep }}}=\frac{\dot{W}_{\text {least }}^{\text {min }}}{\frac{\dot{W}_{\text {sep }}}{\eta_{p p}}+\dot{Q}_{\text {sep }}\left(1-\frac{T_{0}}{T_{s}}\right)}
$$

The important difference between using Equation (74) and Equation (82) is the fact that the work input $\left(\dot{W}_{\text {sep }}\right)$ is divided by the Second Law efficiency of the power plant. This effectively accounts for the fact that the work is not produced reversibly from the heat source, and therefore, cannot be directly compared with the thermal exergy value. If there is no work input, then $\dot{W}_{\text {sep }}=0$ and Equation (83) correctly reduces to Equation (73). Similarly, if there is no heat input, then $\dot{Q}_{\text {sep }}=0$ and Equation (83) reduces to:

$$
\eta_{I I}=\eta_{p p} \frac{\dot{W}_{\text {least }}^{\text {min }}}{\dot{W}_{\text {sep }}}
$$

In the limit of reversible operation for the power plant (i.e., $\eta_{p p}=1$ ), Equation (84) reduces to Equation (73). The Second Law efficiency of the power plant is present in Equation (84) since the work used to power the desalination plant is produced irreversibly. Had the losses in the combustor 
been included in this analysis, both $\dot{W}_{\text {sep }}$ and $\dot{Q}_{\text {sep }}$ in Equation (83) would be divided by the Second

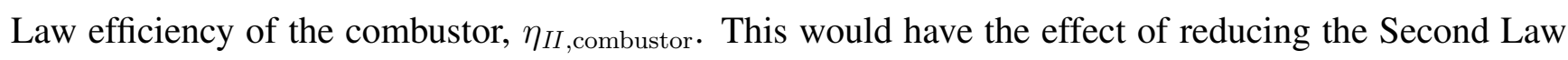
efficiency of the desalination process in proportion to the Second Law efficiency of the combustor. Both the heat and work terms are affected equally since the losses occur prior to the power generation process.

In order to better understand the energetic behavior of both membrane and thermal systems, a parametric study of Equation (83) is conducted in the following three sections for systems using standard seawater as the feed source $\left(35 \mathrm{~g} / \mathrm{kg}, 25^{\circ} \mathrm{C}\right)$. Under these conditions, the minimum least work of separation of seawater per kilogram of product is $2.71 \mathrm{~kJ} / \mathrm{kg}$ [13]. The Second Law efficiency is evaluated under three different conditions: (1) work is the only input, (2) heat is the only input at varying temperatures, (3) heat at $100^{\circ} \mathrm{C}$ is the primary input and the amount of pumping work is varied.

\subsubsection{Desalination Powered by Work}

For desalination systems that are powered entirely using work, $\dot{Q}_{\text {sep }}=0$ and Equation (83) reduces to Equation (84). As a result, it is clear that unless the power plant operates reversibly, a work powered desalination system can never achieve $100 \%$ Second Law efficiency, even if the desalination process is conducted reversibly. This is a direct result of the fact that the primary energy source in the cogeneration scheme is heat to the power plant, not electricity to the desalination plant. For the following study, it is assumed that the power plant is a representative combined cycle plant operating between 1400 and $298.15 \mathrm{~K}$ with a First Law efficiency of $52.8 \%$ and a Second Law efficiency of $67.2 \%$ [43]. The Second Law efficiency of a work-driven desalination plant is shown in Figure 15 as a function of $\dot{W}_{\text {sep }}$ starting at a minimum value of $\dot{W}_{\text {sep }}=\dot{W}_{\text {least }}$.

Figure 15. The Second Law efficiency of a work-driven desalination system operating in a cogeneration scheme can never reach $100 \%$ unless the power plant operates reversibly. Typical values for current reverse osmosis systems are highlighted. Feed water is at $T_{0}=25^{\circ} \mathrm{C}$ and $y_{f}=35 \mathrm{~g} / \mathrm{kg}$.

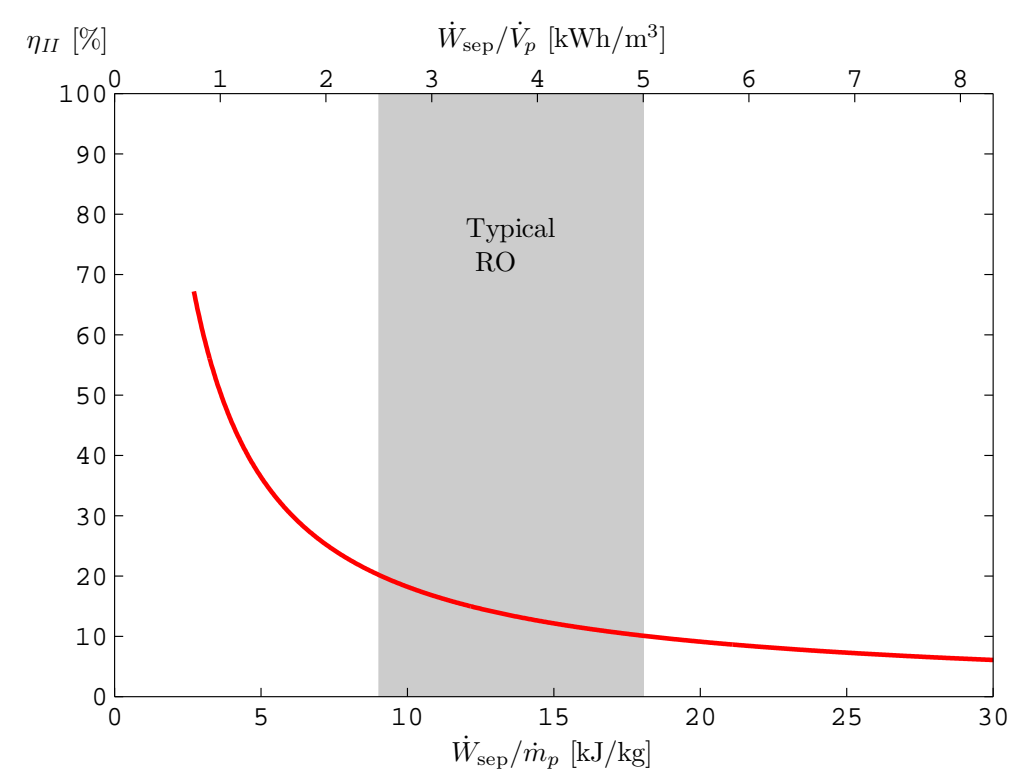


All work-driven systems in this cogeneration scheme pay an energetic penalty on efficiency since the initial energy source (heat) must go through a conversion process (power plant) that operates irreversibly, and therefore, the limiting Second Law efficiency as $\dot{W}_{\text {sep }} \rightarrow \dot{W}_{\text {least }}$ is $\eta_{p p}$, not 1 . If the primary source of energy was considered to be mass of fuel, then the limiting Second Law efficiency would be equal to the product of the Second Law efficiencies of the combustor and the power plant. That is, $\eta_{I I}^{\text {combustor }} \eta_{p p}$. The typical range of operation for current RO technologies is in $2.5-5 \mathrm{kWh}$ and is highlighted in Figure 15. RO systems with energy recovery tend to be on the lower end of this range while systems without energy recovery tend to be on the higher end of this range. Exact values are a function of system design and feed water characteristics [44-49]. This represents Second Law efficiency values ranging in approximately $10 \%-20 \%$.

\subsubsection{Desalination Powered by Heat}

Nearly all large-scale thermal desalination systems are connected to a power plant since large quantities of steam are required to provide heating to the feed. For a thermal desalination plant powered purely using steam at $T_{s}$, Equation (83) reduces to the heat based definition of the Second Law efficiency as given in Equation (72):

$$
\eta_{I I}=\frac{\dot{Q}_{\text {least }}^{\min }}{\dot{Q}_{\mathrm{sep}}}
$$

Note that this expression is not a function of the high temperature heat source, $T_{H}$. This is a result of the assumption made that the entropy generated in the power plant is proportional to the reversible work produced by the power plant operating between two set temperatures. Additionally, the effect of the entropy generation is reflected by $\eta_{p p}$ in the work portion of the energy input, which is equal to zero in this case.

Unlike the work powered case, the thermal desalination plants do not experience the same energetic penalty that is attributed to the irreversibilities within the power production process. Therefore, it is theoretically possible for a reversible thermal desalination plant operating within a cogeneration scheme to achieve $100 \%$ Second Law efficiency. This is shown in Figure 16 in which the Second Law efficiency approaches $100 \%$ as $\dot{Q}_{\text {sep }} \rightarrow \dot{Q}_{\text {least }}$, regardless of steam temperature $\left(T_{S}\right)$. Note that infinitely large heat exchangers and infinitely many stages would be required for a thermal plant to achieve such efficiencies.

Several observations are made from Figure 16. First, at fixed heat of separation, the Second Law efficiency increases with decreasing steam temperature. This is expected since the exergetic value of heat increases with increasing temperature and if the same amount of higher temperature heat (fixed $\dot{Q}_{\text {sep }}$ with rising $T_{s}$ ) is required for a separation process, then the process is utilizing higher exergy heat less efficiently. Second, the minimum heat of separation is a function of steam temperature as is indicated by the fact that it is a function of Carnot efficiency. Third, the rate of increase of Second Law efficiency with respect to a decrease in the heat of separation $\left(-\mathrm{d} \eta_{I I} / \mathrm{d} \dot{Q}_{\text {sep }}\right)$ is most significant at lower values for the heat of separation.

Typical heat requirements for modern MED and MSF plants are shown as grey bands in Figure 16. MED and MED-TVC systems typically have performance ratios from about 10 to 13 and operate with steam around $80^{\circ} \mathrm{C}[44,45,50]$. MSF systems typically have performance ratios from about 6 to 9 and operate with steam around $100^{\circ} \mathrm{C}[44,45]$. This translates to Second Law efficiencies in $7 \%-9 \%$ for 
MED and less than 5\% for MSF. Based on the second observation above, it might seem that operating at a lower steam temperature would enable higher energy efficiency. However, for both MED and MSF plants, the number of effects (or stages) that can practically be built is related to the trade-off between capital and operating expenses [50]. While increasing the number of effects results in increased energy recovery, and therefore increased efficiency and reduced operating costs, it also results in increased capital costs as a result of the increased heat transfer area. As the steam temperature decreases with fixed environment temperature, the temperature pinches in each effect decrease, requiring additional heat transfer area and increased capital cost. At lower steam temperatures, the number of effects that can economically be built is reduced, resulting in higher overall energy requirements and lower overall Second Law efficiency.

Figure 16. The power plant converts heat input into work output, work for the desalination plant, and heat for the desalination plant. Feed water is at $T_{0}=25^{\circ} \mathrm{C}$ and $y_{f}=35 \mathrm{~g} / \mathrm{kg}$.

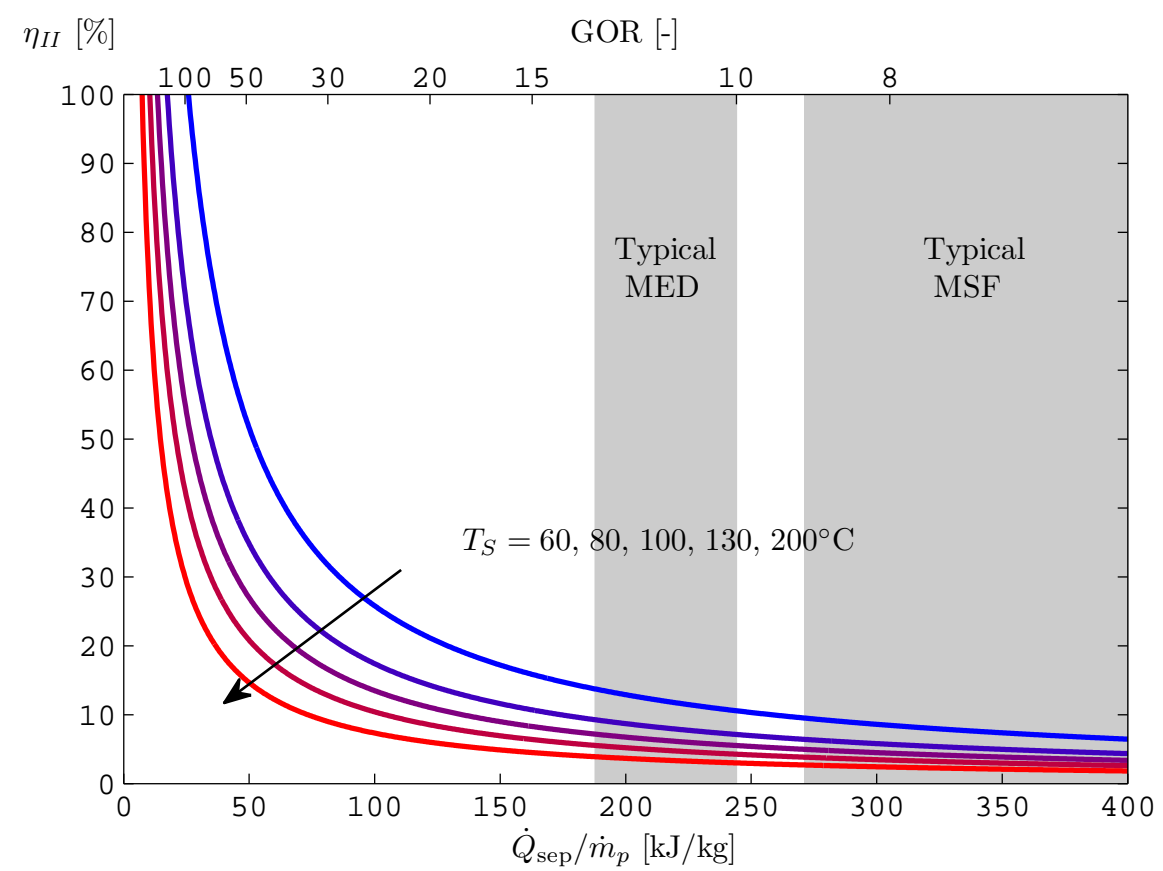

Comparing Figures 15 and 16, it is clear that from a purely energetic point of view, work-driven systems are able to operate more efficiently than thermally driven systems. This point is made even more convincing when it is considered that nearly all thermal systems require substantial work input for running pumps and other equipment. This case is considered subsequently. The comparison between the two figures can only be made because the Second Law efficiency of both the work-driven and thermal driven plants is evaluated using the common energy input, $\dot{Q}_{d}$. If $\eta_{I I}$ for the two plants were not evaluated using the same primary energy input, the comparison between the two figures would not be meaningful.

\subsubsection{Desalination Powered by Co-Generated Heat and Work}

The Second Law efficiency of a thermal desalination plant operating using steam at $100{ }^{\circ} \mathrm{C}$ with pump work requirements ranging in $0-4 \mathrm{kWh}$ is shown in Figure 17. In the case of zero pump work, 100\% Second Law efficiency is theoretically possible. However, once pump work is required, the possible 
Second Law efficiency drops substantially (e.g., approximately $50 \%$ for $0.5 \mathrm{kWh}$ of electrical work to drive pumps). Clearly, regardless of what the required heat of separation is, the additional requirement of pump work results in a decrease in the Second Law efficiency.

Figure 17. Second Law efficiency for a thermal desalination plant requiring work for pumping. Lines for pump work are in increments of $0.5 \mathrm{kWh}$. As the pump work increases, the Second Law efficiency decreases. Feed water is at $T_{0}=25^{\circ} \mathrm{C}$ and $y_{f}=35 \mathrm{~g} / \mathrm{kg}$.

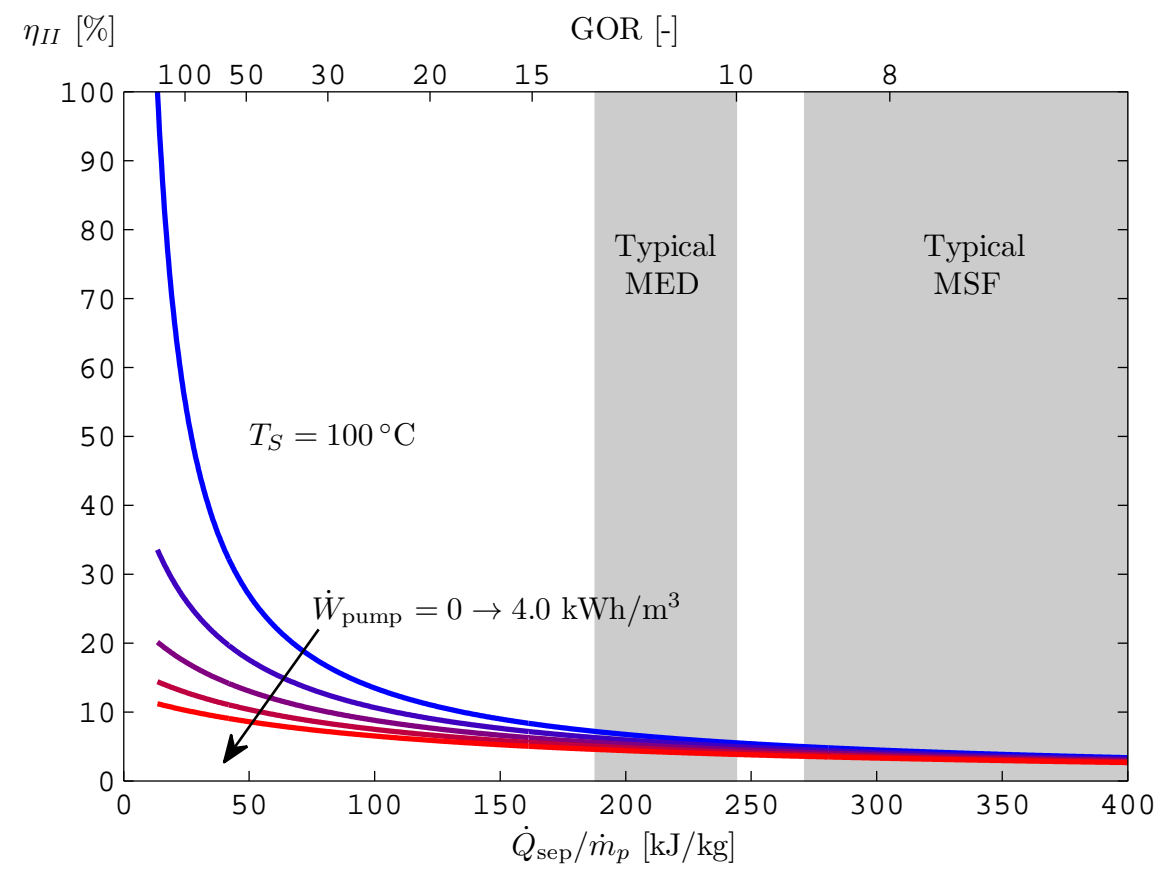

The results shown in Figure 17 are generated based on the assumption that all energy provided to the desalination system originally comes from a common energy source, $\dot{Q}_{d}$. This value of heat input is then substituted into Equations (73) and (74) to get Equation (83). Should a desalination plant have energy inputs from multiple primary energy sources, then the analysis to derive the correct form of $\eta_{I I}$ will change slightly. All energy inputs should be traced to their primary sources (as was done for $\dot{W}_{\text {sep }}$ and $\dot{Q}_{\text {sep }}$ from $\dot{Q}_{d}$ ) and then each primary input should be combined based on the exergetic value as done in Equation (74).

Based on Figures 15 to 17, it is clear that for a desalination plant operating as part of a cogeneration scheme, the work-driven systems (based on currently available technology) always behave in an exergetically more favorably manner than the thermal driven systems (i.e., higher $\eta_{I I}$ ). This is true even when accounting for the energy penalty that comes from converting the source heat to work, and it is even further exemplified when considering that thermal systems typically require large amounts of electrical work for pumping (these are sometimes as high as the work requirements for an RO system).

While it can be concluded that current membrane systems are more efficient from a Second Law point of view, it should not be concluded that there is no role for thermal systems. It should, however, be concluded that exergetically, current work-driven systems are better performing than current thermal systems. Ultimately, several factors are considered when selecting a desalination technology including capital and operating costs, quality of feed water, and existing expertise and infrastructure. While the 
work systems are favored energetically, these other factors can lead to thermal systems being more desirable for a given location or application.

\section{Conclusions}

In this paper, the following conclusions have been reached:

(1) The least exergy of separation is equal to the change in Gibbs free energy of all of the process streams involved in the separation (typically, feed, product, and concentrate). The exergy inputs can be in the form of work, heat, chemical energy (fuel), or some combination thereof.

(2) The least exergy of separation is strictly a function of the composition of the feed and product as well as the recovery ratio and environmental temperature and pressure. If there is an assist stream, it is a function of the assist composition as well. It is not a function of the specific separation process used.

(3) Least work of separation is equivalent to least exergy of separation. Least heat of separation is a strong function of the source temperature related through Carnot efficiency. Similarly, least mass of separation is inversely proportional to the chemical exergy of the fuel.

(4) When separation systems have material input streams in addition to the feed stream, it is possible for the least exergy to be negative. Under such conditions, the separator becomes a work producing system and the magnitude of the least exergy represents the maximum amount of work that can be produced through reversible operation. RO with an FO-based energy recovery device is one such system that relies on an additional material input stream.

(5) Second Law efficiency for a chemical separation process is defined as the useful exergy of the product divided by the actual exergy input. When evaluating the Second Law efficiency, it is essential that the control volume is selected in such a way that only primary energy sources are considered and that all process streams are allowed to come to thermal and mechanical equilibrium (restricted dead state).

(6) In a cogeneration scheme where the primary energy input is heat, a work-driven separation process can never achieve $100 \%$ Second Law efficiency unless the power plant is also reversible, since the work is created through an irreversible process.

(7) Based on currently available technology, work-driven desalination systems are able to achieve a much higher Second Law efficiency than thermally driven systems. From a purely exergetic point of view (based on primary energy input), it is always favorable to produce work to drive an RO system rather than to use MED or MSF. Factors such as cost, feed quality, robustness to difficult conditions, and existing infrastructure may still result in thermal systems being preferred.

\section{Acknowledgments}

The authors would like to thank the King Fahd University of Petroleum and Minerals in Dhahran, Saudi Arabia, for funding the research reported in this paper through the Center for Clean Water and Clean Energy at MIT and KFUPM under project number R13-CW-10. 


\section{References}

1. Oki, T.; Kanae, S. Global hydrological cycles and world water resources. Science 2006, 313, 1068-1072.

2. Smakhtin, V.; Revenga, C.; Döll, P. Taking into account environmental water requirements in global-scale water resources assessments. In Comprehensive Assessment Research Report 2; Comprehensive Assessment Secretariat, International Water Management Institute: Colombo, Sri Lanka, 2004.

3. Shannon, M.A.; Bohn, P.W.; Elimelech, M.; Georgiadis, J.G.; Marinas, B.J.; Mayes, A.M. Science and technology for water purification in the coming decades. Nature 2008, 452, 301-310.

4. Semiat, R. Energy issues in desalination processes. Environ. Sci. Technol. 2008, 42, 8193-8201.

5. El-Sayed, Y.M.; Silver, R.S. Principles of Desalination; Academic Press: New York, NY, USA, 1980; Volume A, chapter 2: Fundamentals of Distillation, pp. 55-109.

6. Spiegler, K.S.; El-Sayed, Y.M. The energetics of desalination processes. Desalination 2001, 134, 109-128.

7. Mistry, K.H.; Lienhard, J.H., V; Zubair, S.M. Effect of entropy generation on the performance of humidification-dehumidification desalination cycles. Int. J. Thermal Sci. 2010, 49, 1837-1847.

8. Alasfour, F.; Darwish, M.; Amer, A.B. Thermal analysis of ME-TVC+MEE desalination systems. Desalination 2005, 174, 39-61.

9. Kahraman, N.; Çengel, Y.A. Exergy analysis of a MSF distillation plant. Energy Convers. Manag. 2005, 46, 2625-2636.

10. Veza, J.M. Mechanical vapour compression desalination plants-A case study. Desalination 1995, $101,1-10$.

11. Cerci, Y. Exergy analysis of a reverse osmosis desalination plant in California. Desalination 2002, 142, 257-266.

12. Sharqawy, M.H.; Zubair, S.M.; Lienhard, J.H., V. Second law analysis of reverse osmosis desalination plants: An alternative design using pressure retarded osmosis. Energy 2011, $36,6617-6626$.

13. Mistry, K.H.; McGovern, R.K.; Thiel, G.P.; Summers, E.K.; Zubair, S.M.; Lienhard, J.H., V. Entropy generation analysis of desalination technologies. Entropy 2011, 13, 1829-1864.

14. Simpson, H.C.; Silver, R.S. Technology of Sea Water Desalination. In Proceedings of Desalination Research Conference; National Academy of Sciences, National Research Council Publication: Washington, DC, USA, 1963; Volume 942, pp. 387-413.

15. Tester, J.W.; Modell, M. Thermodynamics and Its Applications, 3rd ed.; Prentice Hall PTR: Upper Saddle River, NJ, USA, 1997.

16. Bejan, A. Advanced Engineering Thermodynamics, 3rd ed.; John Wiley \& Sons, Inc.: Hoboken, NJ, USA, 2006.

17. McCutcheon, J.R.; McGinnis, R.L.; Elimelech, M. Desalination by ammonia — carbon dioxide forward osmosis: Influence of draw and feed solution concentrations on process performance. J. Membr. Sci. 2006, 278, 114-123. 
18. McGinnis, R.L.; Elimelech, M. Energy requirements of ammonia-carbon dioxide forward osmosis desalination. Desalination 2007, 207, 370-382.

19. Bamaga, O.; Yokochi, A.; Zabara, B.; Babaqi, A. Hybrid FO/RO desalination system: Preliminary assessment of osmotic energy recovery and designs of new FO membrane module configurations. Desalination 2011, 268, 163-169.

20. McGinnis, R.L.; Hancock, N.T.; Nowosielski-Slepowron, M.S.; McGurgan, G.D. Pilot demonstration of the $\mathrm{NH} 3 / \mathrm{CO} 2$ forward osmosis desalination process on high salinity brines. Desalination 2013, 312, 67-74.

21. Mistry, K.H.; Mitsos, A.; Lienhard, J.H., V. Optimal operating conditions and configurations for humidification-dehumidification desalination cycles. Int. J. Thermal Sci. 2011, 50, 779-789.

22. Mistry, K.H.; Narayan, G.P.; Mitsos, A.; Lienhard, J.H., V. Optimization of Multi-pressure Humidification-dehumidification Desalination Using Thermal Vapor Compression and Hybridization. In Proceedings of the 21st National \& 10th ISHMT-ASME Heat and Mass Transfer Conference; Indian Society for Heat and Mass Transfer and American Society for Mechanical Engineers, Chennai, India, 27-30 December 2011; Number ISHMT_USA_015, pp. 1-9.

23. Narayan, G.P.; Sharqawy, M.H.; Summers, E.K.; Lienhard, J.H., V; Zubair, S.M.; Antar, M. The potential of solar-driven humidification-dehumidification desalination for small-scale decentralized water production. Renew. Sustain. Energy Rev. 2010, 14, 1187-1201.

24. Narayan, G.P.; Sharqawy, M.H.; Lienhard, J.H., V; Zubair, S.M. Thermodynamic analysis of humidification dehumidification desalination cycles. Desalination Water Treat. 2010, 16, 339-353.

25. Narayan, G.P.; John, M.G.S.; Zubair, S.M.; Lienhard, J.H., V. Thermal design of the humidification dehumidification desalination system: An experimental investigation. Int. J. Heat Mass Transf. 2013, 58, 740-748.

26. Bajpayee, A.; Luo, T.; Muto, A.; Chen, G. Very low temperature membrane-free desalination by directional solvent extraction. Energy Environ. Sci. 2011, 4, 1672-1675.

27. Luo, T.; Bajpayee, A.; Chen, G. Directional solvent for membrane-free water desalination-A molecular level study. J. Appl. Phys. 2011, 110, 054905.

28. Mistry, K.H.; Lienhard, J.H., V. Effect of Nonideal Solution Behavior on Desalination of a Sodium Choloride $(\mathrm{NaCl})$ Solution and Comparison to Seawater. In Proceedings of ASME 2012 International Mechanical Engineering Congress and Exposition, Houston, USA, 9-15 November 2012; American Society of Mechanical Engineers; Number IMECE2012-88261.

29. Mistry, K.H.; Lienhard, J.H., V. Effect of nonideal solution behavior on desalination of a sodium choloride $(\mathrm{NaCl})$ solution and comparison to seawater. J. Energy Resour. Technol. 2013, doi: 10.1115/1.4024544.

30. Mistry, K.H.; Hunter, H.A.; Lienhard, J.H., V. Effect of composition and nonideal solution behavior on desalination calculations for mixed electrolyte solutions with comparison to seawater. Desalination 2013, 318, 34-47.

31. The International Association for the Properties of Water and Steam, Release on the IAPWS Formulation 2008 for the thermodynamic properties of seawater; Berlin, Germany, 2008; 1-19. 
32. Feistel, R. A Gibbs function for seawater thermodynamics for -6 to $80{ }^{\circ} \mathrm{C}$ and salinity up to $120 \mathrm{~g} \mathrm{~kg}^{-1}$. Deep Sea Res. Part I Oceanogr. Res. Pap. 2008, 55, 1639-1671.

33. Sharqawy, M.H.; Lienhard, J.H., V; Zubair, S.M. Thermophysical properties of seawater: A review of existing correlations and data. Desalination Water Treat. 2010, 16, 354-380.

34. Sharqawy, M.H.; Lienhard, J.H., V; Zubair, S.M. Thermophysical properties of seawater. 2012. Available online: http://web.mit.edu/seawater (accessed on 17 July 2012).

35. Moran, M.J. Availability Analysis: A Guide to Efficient Energy Use, corrected ed.; ASME Press: New York, NY, USA, 1989.

36. Singh, R. Sustainable fuel cell integrated membrane desalination systems. Desalination 2008, 227, 14-33.

37. Al-Hallaj, S.; Alasfour, F.; Parekh, S.; Amiruddin, S.; Selman, J.; Ghezel-Ayagh, H. Conceptual design of a novel hybrid fuel cell/desalination system. Desalination 2004, 164, 19-31.

38. Liberman, B. Present and Future: Energy Efficient Seawater Desalination. Presented at International Desalination Association Conference on Desalination: An Energy Solution, Huntington, California, CA, USA, 2-3 November 2010; Number IDA_HB2010-Liberman.

39. Banchik, L.D.; Lienhard, J.H., V. Thermodynamic Analysis of a Reverse Osmosis Desalination System Using Forward Osmosis for Energy Recovery. In Proceedings of ASME 2012 International Mechanical Engineering Congress and Exposition, Houston, USA, Country, 9-15 November 2012; American Society of Mechanical Engineers, Number IMECE2012-86987.

40. Post, J.W.; Veerman, J.; Hamelers, H.V.; Euverink, G.J.; Metz, S.J.; Nymeijer, K.; Buisman, C.J. Salinity-gradient power: Evaluation of pressure-retarded osmosis and reverse electrodialysis. J. Membr. Sci. 2007, 288, 218-230.

41. Mistry, K.H. Second Law Analysis and Optimization of Humidification-Dehumidification Desalination Cycles. MSc thesis, Massachusetts Institute of Technology, Cambridge, MA, USA, 2010.

42. McGinnis, R.L. Nagare, Storrs, USA Personal Communication, 2013.

43. Moran, M.J.; Shapiro, H.N. Fundamentals of Engineering Thermodynamics, 6th ed.; John Wiley \& Sons, Inc.: New Jersey, NJ, USA, 2007.

44. Global Water Intelligence. DesalData.com. 2013. Available online: http://desaldata.com (accessed on 1 April 2013).

45. Miller, J.E. Review of Water Resources and Desalination Technologies; Technical Report SAND 2003-0800; Sandia National Laboratories: Livermore, CA, USA, 2003.

46. Crisp, G.J. Actual Energy Consumption and Water Cost for the SWRO Systems at Perth. Presented at International Desalination Association Conference on Desalination: An Energy Solution, Huntington, California, CA, USA, 2-3 November 2010; Number IDA_HB2010-Crisp.

47. Stover, R.L. Isobaric Energy Recovery Technology-History and Future Opportunities. Presented at International Desalination Association Conference on Desalination: An Energy Solution, Huntington, California, CA, USA, 2-3 November 2010; Number IDA_HB2010-Stover.

48. Stover, R.L. Seawater reverse osmosis with isobaric energy recovery devices. Desalination 2007, 203, 168-175. 
49. Fritzmann, C.; Löwenberg, J.; Wintgens, T.; Melin, T. State-of-the-art of reverse osmosis desalination. Desalination 2007, 216, 1-76.

50. Mistry, K.H.; Antar, M.A.; Lienhard, J.H., V. An improved model for multiple effect distillation. Desalination Water Treat. 2013, 51, 807-821.

(C) 2013 by the authors; licensee MDPI, Basel, Switzerland. This article is an open access article distributed under the terms and conditions of the Creative Commons Attribution license (http://creativecommons.org/licenses/by/3.0/). 